\title{
Stem Cell Therapy for Burns: Story so Far
}

\author{
Najath Abdul Kareem' \\ Ayesha Aijaz' \\ Marc G Jeschke ${ }^{1-4}$
}

'Sunnybrook Research Institute, Toronto, ON, Canada; ${ }^{2}$ Department of Surgery,

Division of Plastic Surgery, University of Toronto, Toronto, ON, Canada;

${ }^{3}$ Department of Immunology, University of Toronto, Toronto, ON, Canada; ${ }^{4}$ Ross Tilley Burn Centre, Sunnybrook Health Sciences Centre, Toronto, ON, Canada

Correspondence: Marc G Jeschke

Ross Tilley Burn Centre, Sunnybrook

Health Sciences Centre, 2075 Bayview

Ave, Rm D704, Toronto, ON, M4N 3M5,

Canada

Tel + | 416-480-6703

$\mathrm{Fax}+\mid$ 4|6-480-6763

Email marc.jeschke@sunnybrook.ca

\begin{abstract}
Burn injuries affect approximately 11 million people annually, with fatalities amounting up to 180,000 . Burn injuries constitute a global health issue associated with high morbidity and mortality. Recent years have seen advancements in regenerative medicine for burn wound healing encompassing stem cells and stem cell-derived products such as exosomes and conditioned media with promising results compared to current treatment approaches. Sources of stem cells used for treatment vary ranging from hair follicle stem cells, embryonic stem cells, umbilical cord stem cells, to mesenchymal stem cells, such as adipose-derived mesenchymal stem cells, bone marrow-derived mesenchymal stem cells, and even stem cells harvested from discarded burn tissue. Stem cells utilize various pathways for wound healing, such as PI3/AKT pathway, WNT- $\beta$ catenin pathway, TGF- $\beta$ pathway, Notch and Hedgehog signaling pathway. Due to the paracrine signaling mechanism of stem cells, exosomes and conditioned media derived from stem cells have also been utilized in burn wound therapy. As exosomes and conditioned media are cell-free therapy and contain various biomolecules that facilitate wound healing, they are gaining popularity as an alternative treatment strategy with significant improvement in outcomes. The treatment is provided either as direct injections or embedded in a natural/artificial scaffold. This paper reviews in detail the different sources of stem cells, stem cell-derived products, their efficacy in burn wound repair, associated signaling pathways and modes of delivery for wound healing.
\end{abstract}

Keywords: stem cells, burn injury, exosomes, conditioned media, wound healing

\section{Introduction}

Worldwide burn injuries affect 11 million people every year, corresponding to at least 30,000 people suffering burn injuries every day ${ }^{1}$ with annual fatalities amounting up to $180,000 .^{1}$ Although burn injuries are decreasing in highincome countries, the numbers are still high in low- and middle-income areas with $90 \%$ of burns occurring in these areas. While burn injuries generally demonstrate a bimodal age distribution with high incidence in children and middle-aged working people, burn injuries in the elderly population are associated with a tremendously high mortality rate. ${ }^{1}$ Thus, burn constitutes an important global health issue correlated with high morbidity, mortality and debilitating lifelong psychological and economic impact.

Irrespective of burn etiology, age or gender, the most important aspects of burn care are wound coverage and subsequent healing, which determine the severity of local and systemic responses, thus determining the survival or death of a burn patient. $^{2}$ In the event of non-healing burn wounds, wound infection and sepsis are the central morbidities leading to a substantially increased mortality. ${ }^{3}$ The current standard of care is burn excision within 72-hour post-injury. Early excision of burn wounds reduces the source of inflammatory stimuli and hypermetabolic responses, ${ }^{4}$ 
decreasing systemic stress not only during acute hospitalization but also preventing pathological dermal and epidermal regeneration. While this establishes a strong evidence for early removal of burn wounds, the challenge is how to cover these burn wounds. Currently, various skin and skin-derived materials are used to cover these open wounds but at this time no gold standard exists. ${ }^{1-5}$ This review focuses on current treatment strategies paying particular attention to stem cell and stem cell-derived therapies.

First, we discuss the burn wound healing cascade in the context of implications for stem cell therapy, the sources of stem cells being utilized in burn wound healing, and their characteristic differences in their mechanism of action and major pathways. An overview of the current modes of delivery of stem cells for wound healing is also presented. Finally, we explore the opportunities offered by biologics products derived from stem cells for wound healing. In the final section, clinical trials and human case studies conducted using stem cells for burns are also explained.

\section{Current Treatment Approaches for Burn Wounds}

Burns are caused by various sources, such as radiation, cold, heat, chemical and electric burns. The goal of the treatment of burns is to restore the damaged skin to its original anatomical morphology and physiological function. Burn wound care, based on the severity of the injury, is addressed at different levels - prevention of infection, surgical management, permanent or temporary wound coverage, and scar mitigation, which ultimately determines survival and prognosis of the burn patient. ${ }^{7}$ Severe burns result in damage to skin structures and function, as well as the loss of cell progenitors necessary for regeneration and restoration of the skin. Surgical management of burn wounds encompasses debriding necrotic tissue to prevent burn wound sepsis followed by definitive wound coverage with autologous split-thickness skin grafts harvested from healthy donor sites (Figure 1A). However, autologous skin grafts are not always an option, particularly in the case of large burns with limited donor site availability or in the presence of bacterial load on the wound bed. In such
A
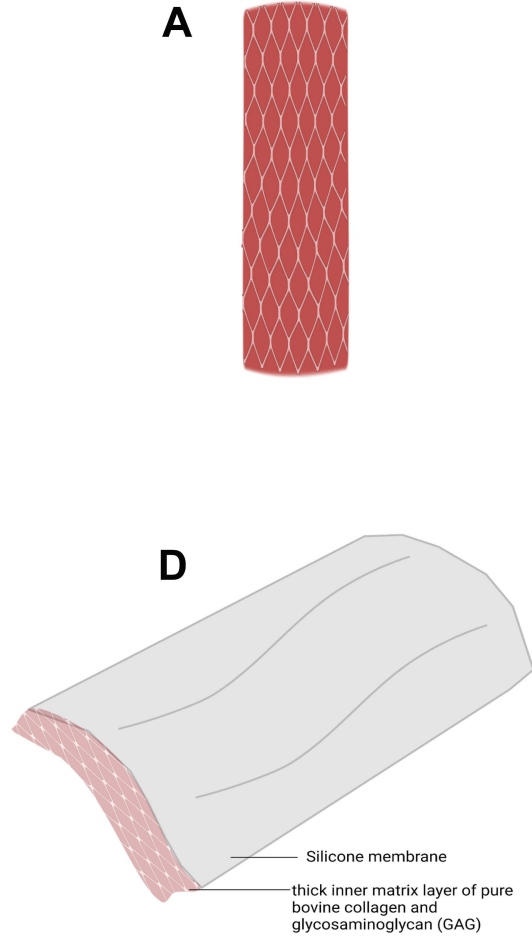

B

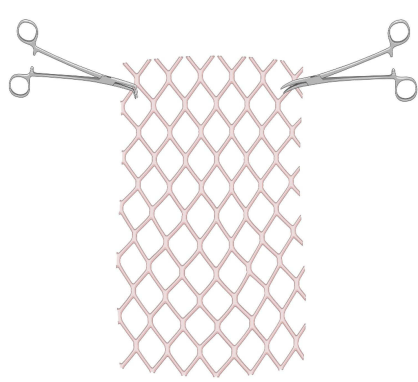

E

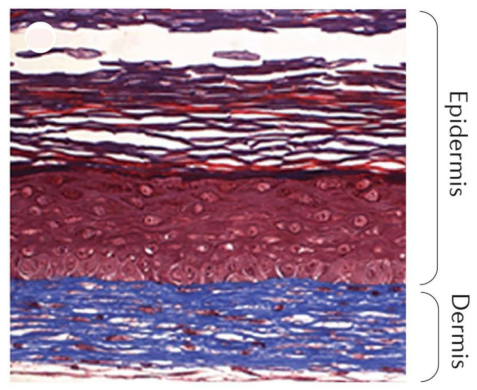

C
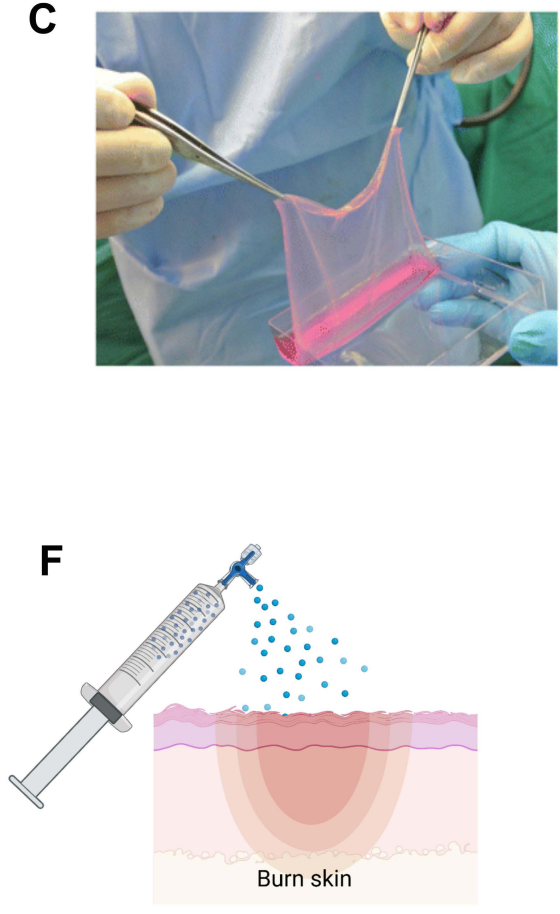

Figure I Current treatment approaches for burn wound coverage.

Notes: (A) Autologous split-thickness skin graft. (B) AlloSkin ${ }^{T M}$ skin allograft. (C) Cultured epithelial autograft. Reproduced from: Chua AWC, Khoo YC, Tan BK, Tan KC, Foo CL, Chong SJ. Skin tissue engineering advances in severe burns: review and therapeutic applications. Burns \& Trauma. 2016;4:s41038-016-0027-y. ${ }^{121}$ Copyright @ 2016, Oxford University Press. Creative Commons CC BY 4.0 (https://creativecommons.org/licenses/by/4.0/legalcode). (D) Integra ${ }^{\circledR}$ Dermal Regenerative Template. (E) Selfassembled bilayer skin substitute of dermal and epidermal structures. Data from Rangatchew et al. ${ }^{19}$ (F) Recell/cell spray which sprays a suspension of skin cells directly to wounded area. Created with Biorender. 
instances, wounds are temporarily covered with allografts from human cadaver skin or porcine skin xenografts or dermal analogs (Figure 1B), until definitive coverage with autologous skin grafts or artificial skin substitutes is pursued. Artificial skin substitutes (Figure 1D) serve as provisional matrices for cellular infiltration, proliferation and wound neovascularization. Among these, the most notable skin substitutes include cultured epithelial autografts (CEA) composed of autologous keratinocytes in a fibrin mesh (Figure 1C) and autologous bilayered self-assembled skin substitute fabricated from autologous fibroblasts and keratinocytes (Figure 1E). Although both these products offer autologous alternatives to split-thickness autografts, fragility, high cost and long production costs have prohibited their clinical applicability. Other approaches for wound coverage include cell sprays (ReCell) (Figure 1F) and skin guns (RenovaCare) to deliver autologous cells to the wound bed to promote wound reepithelialization, which albeit are faced with limitations in applicability to superficial burns and lack of clinical data, respectively. Three-dimensional (3D) bioprinting has also been employed to reconstruct skin through layer-by-layer deposition of cells with scaffolding materials over the injured areas.

These disadvantages thrust the need for alternative wound coverage materials as current materials are either ineffective, pose a chance for immune rejection, timeconsuming, expensive or are acellular. ${ }^{6}$ These limitations lead to the idea of using stem cells either directly or within a scaffold/delivery matrix to augment the healing process.

\section{Implications of Stem Cells in Burn Wound Healing}

The wound healing cascade consists of a delicate balance of cytokines, chemokines, and growth factors. Accordingly, targeting of one phase or signaling molecule (cytokines, chemokines, or growth factors) cannot result in effective healing and tissue regeneration. Current treatments with skin substitutes are not capable of generating fully functional skin after a burn injury and neither do they directly target the different phases of wound healing or release of chemokines or cytokines to influence healing. While administration of only the growth factors has been employed for burn treatment, however, several disadvantages exist. High levels of Vascular Endothelial Growth Factor (VEGF) can cause edema and edema-associated burn complications and increase the risk of tumor formation. ${ }^{8}$ Epidermal Growth Factor (EGF) and Platelet Derived Growth Factor (PDGF) can cause hypertrophic scarring. ${ }^{9,10}$ The complexity of molecular pathways also limits the use of specific growth factors for treatment. Therefore, multiple growth factor systems with sustained release need to be developed. The use of stem cells for burn wound care is justified in this case as stem cells are able to secrete all these growth factors in a sustained manner, respond to local stimuli and influence the wound microenvironment to promote wound healing. Use of stem cells in burn wound healing has shown bright prospects through accelerated healing, improved scar outcomes, better regeneration of skin and its appendages, modulation of inflammatory response and reduction of fibrosis and infection. $^{11}$

The therapeutic potential of stem cells for burn wound healing arises from their ability to modulate the release of the chemokines, cytokines, and growth factors necessary for wound healing. Furthermore, it is increasingly being accepted that rather than post-engraftment differentiation and proliferation, the therapeutic effects of stem cells lie in the secretion of paracrineor signaling molecules. ${ }^{12}$ Proteomic analysis of bone marrow derived mesenchymal stem cells (BM-MSCs), adipose-derived mesenchymal stem cells (AD-MSCs), and umbilical cord-derived mesenchymal stem cells (UC-MSCs) show the secretion of chemokines, cytokines and growth factors which promote migration and proliferation of fibroblasts, endothelial cells, and keratinocytes. ${ }^{12}$ MSCs thus possess a secretome profile capable of promoting wound healing and therefore stem cell products such as their exosomes and conditioned media have also been utilized for burn wound therapy. ${ }^{13}$

Furthermore, a consistent challenge of long-term outcome after burn is scarring. Burns cause pathological scarring, especially in deep partial thickness or full thickness burns. Pathological scars are thick, cause pain, itching and contractures, and lead to limited functionality. ${ }^{1}$ Stem cells have also shown potential in inhibiting the activity of keloid fibroblasts through paracrine signaling, thus proving their potential in scar management in long-term burn injury care. Conditioned medium derived from AD-MSCs was used in a keloid implantation animal model which showed reduced inflammation and fibrosis. ${ }^{14}$ Similar results have been noted with the use of BMSC-derived conditioned medium. ${ }^{15}$ These results provide evidence and superiority of stem cells over traditional methods employed for burn care. 


\section{Sources of Stem Cells in Burn Wound Care}

Depending on the stage of development, stem cells can come from either embryonic tissue or from adults and are capable of differentiating into a wide range of cell types. Stem cells are divided into totipotent, pluripotent, and multipotent stem cells depending on their differentiation ability. While totipotent cells can differentiate into any type of cells including embryonic and extra-embryonic cells, pluripotent stem cells can only form germ-line cells and somatic cells. Multipotent stem cells can differentiate into specific cell types, tissues, or organs. Different sources of stem cells have been utilized in regenerative medicine within the scope of burn wound healing, such as embryonic stem cells (ESC), umbilical cord stem cells (USC), mesenchymal stem cells (MSC) such as bone marrow derived mesenchymal stem cells (BM-MSC), and adipose tissue-derived mesenchymal stem cells (AD-MSC), burn derived mesenchymal stem cells (BD-MSCs), epidermal stem cells (EpSCs), and hair follicle stem cells (HFSCs) (Table 1).

\section{Hair Follicle Stem Cells (HFSC)}

HFSCs are easily accessible, multipotent stem cells capable of rapid proliferation and generation of stratified epidermis and epidermal cells, hair follicle cells, endothelial cells, and keratinocytes. HFSCs show no immune rejection as they have no major histocompatibility complex (MHC) class 1 and immune cells, making them universal donors for cell-based therapy. ${ }^{16}$

HFSC can give rise to epidermis only when the epidermis is wounded or stressed by generating transit amplifying (TA) cells which help in injury repair. ${ }^{16}$ The efficacy of HFSC in wound healing is seen in studies where HFSC treated rats with partially thick burn wounds have shown increased tissue tensile strength and accelerated wound closure rate, ${ }^{16}$ while mice lacking hair follicles exhibit impaired and delayed wound healing, which demonstrates the critical role of HFSCs in wound healing. ${ }^{17}$ Also, clinical study involving application of HFSC to third-degree burns demonstrated increased dermal re-epithelialization. ${ }^{18}$

Subgroups of these cells can migrate from the wound site to repair the damaged skin, reconstruct hair follicles, including the external root-sheath, internal root sheath and hair shaft, as well as the sebaceous gland. ${ }^{16-18}$ These stem cells have the ability to differentiate into keratinocytes. ${ }^{16}$ Meta-analysis study conducted by $\mathrm{Li}$ et al shows that HFSCs were more efficient than other
Table I Various Sources of Stem Cells and Their Characteristics in Burn Wound Healing

\begin{tabular}{|c|c|c|}
\hline Source & $\begin{array}{l}\text { Wound Healing } \\
\text { Mechanism }\end{array}$ & Advantages \\
\hline $\begin{array}{l}\text { Hair follicle } \\
\text { stem cells } \\
\text { (HFSC) }\end{array}$ & $\begin{array}{l}\text { - Generate stratified } \\
\text { epidermis, hair } \\
\text { follicle cells and } \\
\text { keratinocytes }\end{array}$ & Easily accessible \\
\hline $\begin{array}{l}\text { Embryonic stem } \\
\text { cells (ESC) }\end{array}$ & $\begin{array}{l}\text { - Enhance re- } \\
\text { epithelialization, cell } \\
\text { proliferation and } \\
\text { vascularization }\end{array}$ & $\begin{array}{l}\text { Generate all three } \\
\text { germ layers. } \\
\text { Disadvantage: } \\
\text { Ethically controversial }\end{array}$ \\
\hline $\begin{array}{l}\text { Umbilical cord } \\
\text { stem cells (USC) }\end{array}$ & $\begin{array}{l}\text { - Have endothelial } \\
\text { progenitor cells, } \\
\text { hematopoietic and } \\
\text { non-hematopoietic } \\
\text { cells } \\
\text { - Differentiate into } \\
\text { epithelium in vivo } \\
\text { and in vitro } \\
\text { - Reduce inflammation } \\
\text { - Immunomodulatory }\end{array}$ & Non-controversial \\
\hline $\begin{array}{l}\text { Bone marrow- } \\
\text { derived stem } \\
\text { cells (BM-MSC) }\end{array}$ & $\begin{array}{l}\text { - Increases collagen } \\
\text { production and } \\
\text { reduces scar } \\
\text { formation } \\
\text { - Decrease MMP } \\
\text { production }\end{array}$ & $\begin{array}{l}\text { High rate of } \\
\text { proliferation and } \\
\text { differentiation. } \\
\text { Disadvantage: Low } \\
\text { yield }\end{array}$ \\
\hline $\begin{array}{l}\text { Adipose tissue - } \\
\text { derived stem } \\
\text { cells (AD-MSC) }\end{array}$ & $\begin{array}{l}\text { - Promote angiogenesis } \\
\text { - Immunomodulatory } \\
\text { - Reduces scar } \\
\text { formation }\end{array}$ & $\begin{array}{l}\text { High yield and easily } \\
\text { obtainable, can be } \\
\text { isolated from } \\
\text { discarded burned skin }\end{array}$ \\
\hline $\begin{array}{l}\text { Burn-derived } \\
\text { mesenchymal } \\
\text { stem cells (BD- } \\
\text { MSC) }\end{array}$ & $\begin{array}{l}\text { - No tumorigenicity } \\
\text { - Promote re- } \\
\text { epithelialization } \\
\text { - Reduce granulation } \\
\text { - Function unaffected } \\
\text { by thermal damage }\end{array}$ & Safe source \\
\hline
\end{tabular}

cell types in promoting wound healing. ${ }^{19}$ Like HFSC, another type of stem cell derived from the skin is epider$\mathrm{mal} /$ keratinocyte stem cells. These are located in the epidermis and bulge region of hair follicles of the skin making it easily accessible and an excellent source for epidermal reconstitution. ${ }^{20}$

\section{Embryonic Stem Cells (ESCs)}

ESCs are derived from the blastocyst of an embryo and their usage remains limited due to ethical concerns, as 
deriving these cells requires the termination of the embryo. ESCs have the potential to generate all three germ layers. However, due to ethical concerns, use of ESCs remains limited and most of the research uses adult stem cells.

\section{Umbilical Cord Stem Cells (USCs)}

USCs are one of the best sources of stem cells as they have endothelial progenitor cells, as well as hematopoietic and non-hematopoietic cells. Human umbilical cord is the most abundant and non-ethically controversial source of stem cells. ${ }^{21}$ Cord blood contains various stem cell types and can be isolated from different layers of the cord like arteries and veins, the gelatinous supporting matrix known as Wharton's jelly and outer lining. ${ }^{22}$ Stem cells isolated from cord blood are non-hematopoietic stem cells with the ability to differentiate into epithelial cells in vivo and in vitro. ${ }^{22}$

A study conducted by Zhou et al demonstrated that human USC-conditioned medium in hydrogel reduced healing time and area of inflammation, formed wellvascularized granulation tissue, and reduced the formation of fibrotic and hypertrophic scar tissue in third-degree burned mice. ${ }^{23}$ Similarly, stem cells isolated from Wharton's jelly (WJ-MSCs) show a high-yielding source of cells that are young, non-tumorigenic, and immunomodulatory with the capability to regenerate skin and its components. ${ }^{24}$ Studies have shown that human WJ-MSCs can differentiate into sweat gland-like cells, secrete wound-healing promoting factors like VEGF, Transforming Growth Factor (TGF)- $\beta$, PDGF and many others which contribute to wound healing. ${ }^{25}$ Human derived WJ-MSCs have also been shown to promote wound healing through paracrine signaling both in vitro and in vivo in mice. ${ }^{26}$

\section{Mesenchymal Stem Cells (MSCs)}

MSCs have recently become popular in research due to the ethical issues associated with totipotent and pluripotent stem cells. MSCs are adult stem cells derived from various sources, such as adipose tissue, placenta, bone marrow, and amniotic fluid and express CD105, CD73, CD90 and lack the expression of markers, such as CD45, CD35, CD19, CD11b and Human Leukocyte Antigen-DR (HLADR). MSCs are immunologically inactive due to low MHC1 and lack of MHCII. ${ }^{27}$ In addition, MSCs are immunomodulatory and augment the generation of regulatory T-cells and anti-inflammatory macrophage subtypes and have the ability to transdifferentiate, creating a favorable environment for tissue regeneration. They release growth factors and cytokines initiating a balanced inflammatory and anti-inflammatory signal, help in angiogenesis, reduce fibrosis and are anti-apoptotic. MSCs were first isolated in the 1970s from the bone marrow. ${ }^{27}$ Similar cells derived from adipose tissue, umbilical cord/cord blood and Wharton's jelly were subsequently reported. ${ }^{27}$

\section{Bone Marrow Derived Mesenchymal Stem Cells (BM-MSC)}

BM-MSCs are non-hematopoietic and possess a high rate of differentiation and proliferation. Studies show that BMMSCs are recruited to the site of injury and interact with local cells in the skin to regenerate skin. ${ }^{28}$ BM-MSCs are the first type of cells to be used in the context of burn wound therapy, which when applied to wounds on rats showed a decrease in cell infiltration and promoted angiogenesis. $^{27}$

BM-MSCs are shown to have potential in angiogenesis, scarless healing and increased collagen production, all of which are important characteristics of efficient wound healing. Subcutaneous injection of BM-MSCs in mouse models increased capillary density and angiogenesis, secretion of VEGF and demonstrated no tumorigenicity. ${ }^{29}$ Autologous BM-MSCs have shown reduction in scar formation and restoration of elastic fibers in tissue when used for burn wound therapy. ${ }^{30}$ BM-MSCs are also involved in inducing collagen production by fibroblasts $^{31}$ and have been shown to improve wound healing by decreasing the production of MMPs resulting in increased collagen content in the skin. ${ }^{29}$ Likewise, the results of intradermal injection of BM-MSCs locally into the burned area done by Agay et al on pigs inflicted with cutaneous radiation exhibited better vascularization and lymphocyte accumulation in comparison to control pigs with no injection. ${ }^{32}$ BM-MSCs have also been used with scaffolds. BM-MSCs seeded in artificial dermal substitutes also show increased vascular density and reepithelialization in a study conducted by Leonardi et al. ${ }^{33}$ Despite the major advantages, a drawback to BM-MSCs is the limited availability of donors, and low yield. ${ }^{33}$

\section{Adipose Derived Mesenchymal Stem Cells (AD-MSC)}

AD-MSCs are located in the interstitium between adipocytes and vascular endothelium. Stem cells from adipose tissue have been gaining research interest in the past years mainly due to their high yield and their versatility to be incorporated into autografts, allografts, and xenografts. ${ }^{34} \mathrm{It}$ 
is possible to isolate $100 \%$ of resident MSCs from adipose tissue $^{35}$ and retrieval can be done easily without the need for cell culture. ${ }^{36}$ These stem cells can also be isolated from discarded burn $\operatorname{skin}^{37}$ and are able to regenerate all layers of skin.

AD-MSCs are the best option in regenerative medicine as these cells contain macrophages, fibroblasts and endothelial stem cells and are easily obtainable with tremendous pluripotent potential. ${ }^{38}$ They have also shown remarkable results in promoting wound healing and regeneration through angiogenesis and immunomodulation, increased collagen type III deposition and reduction in lymphatic vessels in burned rat models. ${ }^{39}$ Alexaki et al demonstrated the use of AD-MSC in wound healing in mice with improved re-epithelialization by their proliferative effect on keratinocytes. ${ }^{40}$ A study done by Trottier et al demonstrated the ability of AD-MSCs to form wellstructured dermis and epidermis after 14 days on collagen scaffolds. $^{38}$ AD-MSCs also have immunomodulatory effects, such as regulation of chemokines and cytokines like $\mathrm{VEGF}^{41}$ through downregulation of T helper cell (Th) mediated inflammatory response and IL (interleukin)-10 secreting $\mathrm{T}$ regulatory cells (Treg). ${ }^{42}$ Additionally, the use of AD-MSC for burn wound care has demonstrated a reduction in scar formation. ${ }^{43}$

\section{Burn Derived Mesenchymal Stem Cells (BD-MSC)}

Another developing source of stem cells is BD-MSCs obtained from discarded burn tissue, which have shown improved healing in animal models. Since standard burn wound care involves excision and debridement, BD-MSCs are a safe and non-invasive therapeutic option for burn patients. BD-MSCs also do not display any tumorigenicity and detrimental effects both in vitro and in vivo in murine and porcine wound healing models over 30 days. $^{44,45}$ BDMSCs derived from discarded burn tissue can be used as skin substitutes. Porcine studies conducted using bovine scaffold seeded with BD-MSCs to treat deep partial or full thickness burns show increased collagen content, dermal thickness, and epidermal area 14 days after transplantation. $^{44}$ Increased wound closure and enhanced angiogenesis were also shown 4 weeks post transplantation with the use of scaffold seeded BD-MSCs. ${ }^{44}$ Enhanced wound closure, reduction in thickness of keratinocyte layer and decrease in granulation tissue size were observed with potential for decreased scarring. ${ }^{44}$ BD-MSCs extracted from full thickness burns function like other MSCs and are unaffected by thermal damage in terms of important cell functions involved in burn wound healing. ${ }^{46}$

\section{Advantages of Using Stem Cells in Burn Wound Care}

Compared to current strategies employed and different preclinical trials using other methods for burn wound therapy, stem cells for burn injury treatment are superior in many aspects. Stem cells are known to have mainly two actions as per research. First, they help reduce systemic inflammatory response by upregulating anti-inflammatory cytokines and reducing pro-inflammatory cytokines. They can also alter the function of $\mathrm{T}$ cells, B cells, monocytes/macrophages, and natural killer (NK) cells. ${ }^{47}$ Furthermore, stem cells have been shown to improve bacterial clearance. Secondly, stem cells can modulate wound healing. Stem cells seeded into the wound environment can differentiate into myofibroblasts, dermal fibroblasts, antigen presenting cells and lymphoid tissue, as well as stimulate the resident stem cells. ${ }^{48}$ By integrating themselves into the wound, stem cells are generally postulated to play a direct role in wound healing and repair. In vivo studies tracing fluorescent labelled BM-MSCs injected intravenously into the wounded skin of mice show the presence of fluorescent cells after healing positive for markers of pericytes, fibroblasts, endothelial cells, and epidermal keratinocytes. ${ }^{49}$

Additionally, stem cells improve wound regeneration through paracrine signaling. Stem cells secrete at least 30 bioactive molecules that promote wound healing. ${ }^{13}$ The therapeutic efficiency displayed by stem cells can be replicated using cell-free conditioned media derived from stem cells, which points to the paracrine effect of stem cells. AD-MSC conditioned medium has been shown to contain a transcription elongation factor EII3 and Stromal cell Derived factor -1 (SDF-1) which determines the efficiency of wound healing in vivo and in vitro. ${ }^{50,51}$ This ability of stem cells to utilize diverse systemic and local interrelated pathways, rather than a single pathway of action exhibited by specific drugs, is a factor contributing to the superiority of stem cells over other treatment strategies for burn wound healing. They are also defined by their ability to respond to host chemokines, helping in MSC-host endothelial interaction, wound vascularization, reducing microbial activity and strengthening newly formed blood vessels. ${ }^{48}$

Not only have stem cells shown effectiveness in acute care but they have also shown therapeutic potential in scarring. ${ }^{52,53}$ Scarring is one of the long-term outcomes 
after burn and has remained a consistent challenge to overcome. Burn scars tend to be thick, painful and itchy, causing contractures and limited functionality of the injured area. Stem cells help in reducing scars inhibiting the activity of keloid fibroblasts through paracrine signaling. Studies have shown conditioned media derived from AD-MSCs when used in a keloid implantation animal model reduced inflammation and fibrosis. ${ }^{14}$ Similar results have been noted with the use of BM-MSC derived conditioned medium. These results provide evidence and superiority of stem cells over traditional methods employed for burn care. ${ }^{15,27}$

Nevertheless, it is difficult to determine the differences in therapeutic effects between various stem cell sources because of the heterogeneity in macroscopic assessment methods, microscopic features described as well as the different time points considered in the studies. ${ }^{54}$ In both preclinical and clinical trials, although evaluating the safety and efficacy of MSCs in burn wound healing, there is no indication that any specific MSC tissue origin has an advantage in terms of wound healing over the other. $^{11}$

\section{Mechanism of Action of Stem Cells in Burn Wound Healing}

Several pathways have been explored in studies to understand the mechanism of action of stem cells in burn wound healing. Stem cells act in a paracrine fashion to contribute to wound healing. The pathways involved are complex and intertwined. The most researched pathways are given below (Figure 2):

\section{PI3K/AKT Pathway}

The phosphatidylinositol 3 kinase/Protein kinase B (PI3K/ AKT) pathway is the most explored in wound healing research. The growth factors and cytokines secreted during the wound healing process act as upstream extracellular signaling molecules to PI3K/AKT signaling pathway. ${ }^{55}$ The serine/threonine kinase AKT is an important part of the PI3K signaling pathway. AKT helps in many cellular functions, such as cell metabolism, growth, survival, senescence, angiogenesis and apoptosis. ${ }^{55}$ It also helps to regulate the expression of growth factors, such as VEGF, fibroblast growth factor (FGF) and EGF. Reduced function of this pathway is known to prevent cell proliferation and wound healing. ${ }^{55}$

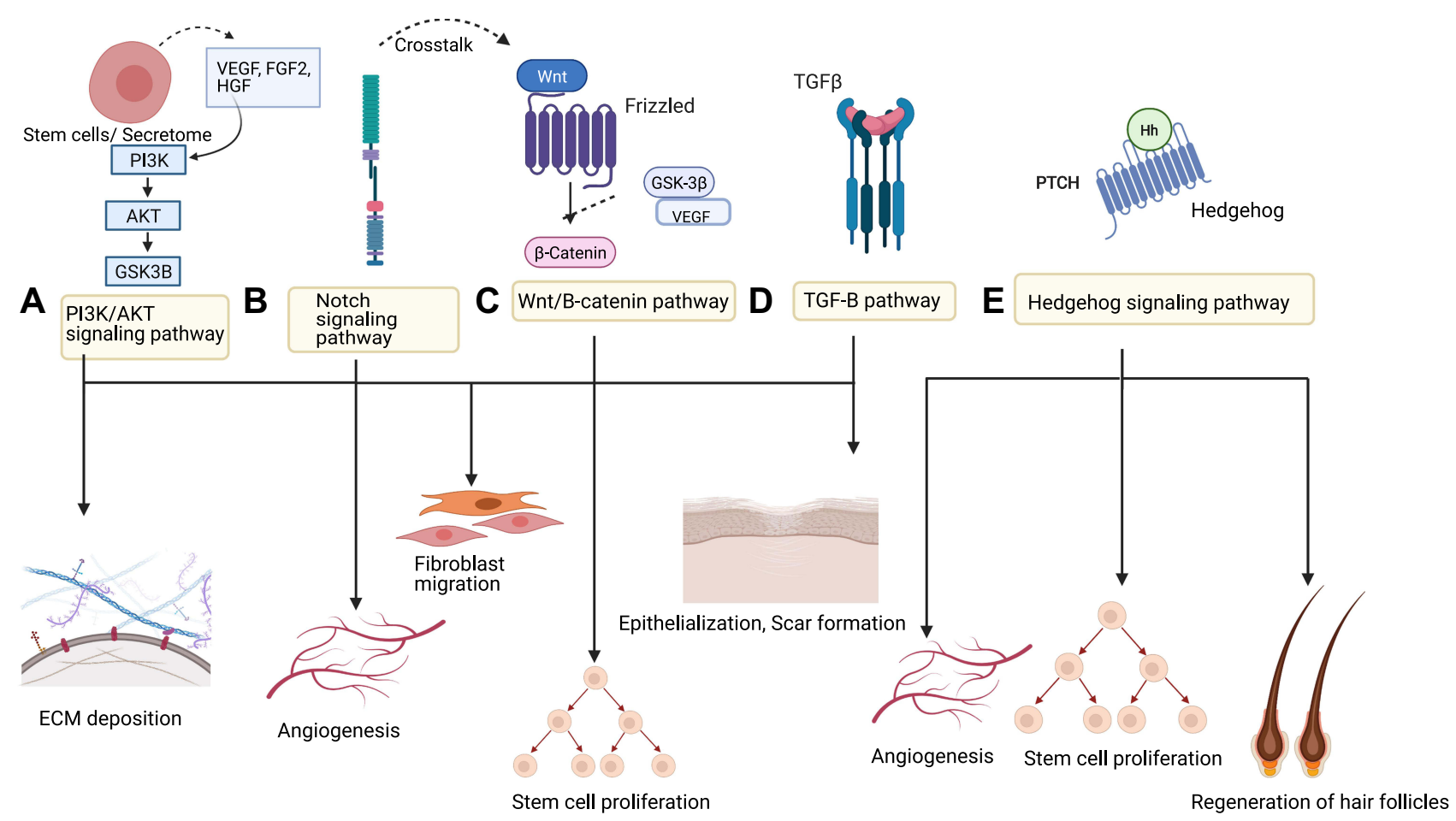

Figure 2 Different pathways used by stem cells in wound healing.

Notes: (A) PI3K/AKT pathway. (B) Notch Pathway. (C) Wnt/B-catenin pathway. (D) TGF- $\beta$ pathway. (E) Hedgehog pathway. 
MSCs can enhance wound healing by inhibiting inflammatory response and cell apoptosis, promoting cell proliferation and angiogenesis, and regulating ECM remodeling. ${ }^{56}$ The role of PI3K/AKT pathway in the survival of MSCs has been studied by overexpressing the AKT1 molecule in MSCs. ${ }^{57}$ The results showed that the overexpression of the molecule improved MSC survival after transplantation into the heart in rats. ${ }^{57,58}$ Similar results have been achieved in larger animal models, thereby highlighting the importance of this pathway in MSC survival. In case of MSC proliferation, activation of the PI3K/Akt pathway is necessary as a mediator of other factors that increase the proliferation of stem cells. ${ }^{57}$ The association of the PI3K/Akt pathway with MSC migration has also been studied. Furthermore, the ability of MSCs to secrete cytokines to facilitate wound healing as well as differentiation is also known to be regulated by PI3K/Akt activity. ${ }^{57}$

The protective effect of stem cells is mediated by paracrine signaling that directs their regenerative mechanism. A study conducted by Li et al shows that human amniotic mesenchymal stem cells (hAMSC) and its conditioned media transplantation on mice with second-degree burn injury model can enhance proliferation, inhibit apoptosis of skin cells, and promote angiogenesis through PI3K/AKT signaling pathway. ${ }^{56}$ Similarly, migration of fibroblasts during wound healing also utilizes the PI3K/ AKT pathway. ${ }^{59}$ PI3K/AKT inhibitors inhibited fibroblast migration and differentiation of myofibroblasts in rats. ${ }^{71}$ The pathway is also found to enhance keratinocyte migration in AKT dependent manner. ${ }^{61}$

\section{WNT- $\beta$ Catenin Signaling}

WNT signaling plays an important role in wound healing and stem cell function. During development, WNTs are involved in skin development, such as formation of dermis, and skin appendages like hair follicles which provide evidence for their potential involvement in skin regeneration following an injury. During the early phases of wound healing, different types of WNTs, such as WNT 1,2,4,5a and $10 \mathrm{~b}$ are found for up to 7 days after wounding in murine models. ${ }^{62}$ It is known to work in parallel with Notch signaling to regulate wound healing. For example, studies have shown proliferation of ESCs during wound healing is enhanced through Wnt/ $\beta$-catenin and Notch signaling via $c-M y c$ and Hesl, downstream targets of Wnt/ $\beta$-catenin and Notch pathways. Additionally, canonical Wnt signaling is known to play an important role in
MSC self-renewal and hair follicle formation in response to injury. ${ }^{63} \mathrm{Wnt} / \beta$-catenin pathway is also involved in the proliferation of epidermal stem cells, migration of epithelial cells ${ }^{64,65}$ and differentiation into keratinocytes. ${ }^{66} \beta$ catenin does affect fibroblast migration during the proliferative phase of wound healing, elevating protein levels and transcriptional activity of fibroblasts during the proliferative phase and bringing it down during the remodeling phase. It is also shown in studies that mice with fibroblast-specific conditional deletion of Glycogen synthase kinase 3 (GSK3 $\beta$ ) show elevated levels of $\beta$ catenin causing increased dermal collagen deposition, scarring and myofibroblast formation. ${ }^{67}$ The utilization of canonical Wnt signaling by stem cells to regulate wound healing can also be elucidated from the fact that levels of $\beta$-catenin are stimulated by growth factors like TGF- $\beta{ }^{68}$ The paracrine effect of stem cells to release these growth factors simultaneously affecting $\beta$-catenin levels suggest the potential employment of this signaling pathway by stem cells to enhance wound healing.

\section{TGF- $\beta$ Pathway}

TGF- $\beta$ pathway is thought to be crucial in wound healing. The three isoforms of TGF- $\beta$ (TGF- $\beta 1$, TGF- $\beta 2$, TGF- $\beta 3$ ) are involved in wound healing and scar formation. ${ }^{69}$ These isoforms differ in their level of expression, biological activity, and their duration in the wounds. ${ }^{70}$ TGF- $\beta 3$ is known to support scarless healing and regulates epidermal and dermal cell movement during wound healing, ${ }^{69}$ whereas TGF- $\beta 1$ is involved in fibrosis. ${ }^{71}$ TGF- $\beta 1$ exerts its effect by activating downstream molecules like Smad2 and Smad3. TGF- $\beta$ pathway can alter the ability of wound healing and involves crosstalk between dermis and epidermis to influence the healing outcome. ${ }^{62}$

Stem cells employ this pathway during burn wound repair. TGF- $\beta$ pathway is involved in recruiting stem cells for tissue regeneration. ${ }^{6}$ Topical application of TGF $\beta 1$ in wounded aged rats showed dermal healing aspects, such as extracellular matrix (ECM) deposition, fibroblast migration and proliferation, angiogenesis, cell infiltration and epithelial closure of wounds by regulating different cell types including stem cells. ${ }^{71}$ The utilization of TGF- $\beta$ pathway by MSCs can be understood by the wound healing effects of conditioned media derived from human amniotic fluid-derived MSCs, which results in proliferation and migration of dermal fibroblasts in mouse excisional wound model. ${ }^{72}$ Similar results are also seen with exosomes derived from human BM-MSCs which 
utilizes the TGF- $\beta$ pathway to stimulate wound healing. ${ }^{73}$ The importance of TGF- $\beta$ pathway in wound healing is demonstrated by the defects in dermal wound healing exhibited by mice deficient in TGF- $\beta$ pathway components. $^{74}$ Dysregulation in the TGF- $\beta$ pathway shows scarring, fibrosis, irregular deposition, and synthesis of collagen. $^{75}$

\section{Notch Pathway}

Growing research suggests the importance of Notch signaling pathway in wound healing. The Notch pathway acts through the interaction of Notch receptors with membranebound ligands of Delta and Jagged families. This pathway is important in cell-fate decision and differentiation in many tissues like skin. High levels of activation of Notch signaling promotes differentiation of epidermal stem cells into keratinocytes, increasing vessel density in endothelial cells and thus accelerating wound healing. ${ }^{76,77}$ Jagged1, the ligand with which Notch receptor interacts, is shown to play an important role in regulating the differentiation of epidermal stem cells, helping in wound healing and scar formation. ${ }^{68}$ Research shows the importance of the Notch pathway in wound repair by showing the expression of Jagged1 and Notch1 in the healing epidermis of wounded human skin grafted onto mice. ${ }^{78}$ Furthermore, Notch signaling pathway is also known to regulate stem cell adhesion. Given the paracrine nature of the mechanism of stem cells, exosomes derived from fetal dermal MSCs activate Notch signaling pathway in mouse models to enhance wound healing. ${ }^{79}$ Notch signaling pathway is also known to be a key factor in maintaining the stemness of MSCs and preventing senescence. ${ }^{80,81}$

This pathway is known to engage in crosstalk with the Wnt/ $\beta$-catenin pathway and hedgehog pathway. In vitro scratch wound assays treated with a Notch activator or inhibitor show the pro-migratory effects of Notch on fibroblasts and vascular endothelial cells. ${ }^{82}$ Notch signaling is also involved in the inflammatory phase of wound healing, where it regulates macrophage behavior. ${ }^{83}$ Evidence shows that the Notch signaling pathway is also involved in angiogenesis, and ECM production during wound healing. ${ }^{78}$

\section{Hedgehog Pathway}

The role of Hedgehog signaling in wound repair has not been explored extensively, although it is a promising area of research based on available evidence. Sonic hedgehog pathway (Shh) stimulates mouse embryonic stem cell proliferation (mESC) and accelerates wound healing by indirectly upregulating VEGF, allowing for angiogenesis to promote blood flow to the injured skin. ${ }^{85}$ The utilization of Shh pathway by stem cells in wound healing was demonstrated by the experiment done by Suh \& Han in 2015. They showed that mouse embryonic stem cells (mESCs) utilize Shh pathway to accelerate skin wound healing by indirectly regulating angiogenesis. ${ }^{84}$ Similarly, the angiogenic potential of Hedgehog pathway is demonstrated by the study conducted by Zavala et al, which showed that WJ-MSC utilized the Shh pathway to promote angiogenesis in vivo. ${ }^{85}$ The involvement of Shh in dermal healing is further demonstrated by the presence of Shh in regenerated hair follicles. ${ }^{86}$ This is an important characteristic as failure to regenerate hair follicles that are damaged due to injury is a challenge in cutaneous regenerative medicine. The capability of stem cells to utilize Shh pathway to regenerate hair follicles following a burn injury is noteworthy and further demonstrates the need for the employment of stem cells for burn wound therapy.

\section{Biologics: Use of Secretome in Burn Wound Healing}

Another interesting application of stem cells has been the use of acellular derivatives from cells, otherwise known as secretome. Secretome consists of proteins, nucleic acids, exosomes, proteasomes, membrane vesicles and microRNA. The use of purified exosomes or conditioned media has shown better therapeutic effects and reduces the risks associated with the use of living cells, such as tumorigenicity, transmission of infection and immune compatibility. ${ }^{73,87-89}$

\section{Exosomes Derived from Stem Cells}

Exosomes are present in growth media of stem cell cultures $^{87}$ and present the advantage of retaining the characteristics of their source, helping in repair and regeneration of tissue, maintaining homeostasis and accelerating healing. ${ }^{88}$ Exosomes are vesicles within humoral environments containing proteins, lipids, nucleic acids, microRNAs, and other bioactive molecules; they can be readily isolated from MSCs because of the ability of MSCs to produce them. They can exert huge biological effects because of their ability to fuse with target cells. ${ }^{87}$ Additionally, because exosomes are protected by their plasma membrane, they are easy to store and transport as bioactive molecules. ${ }^{87}$ The 


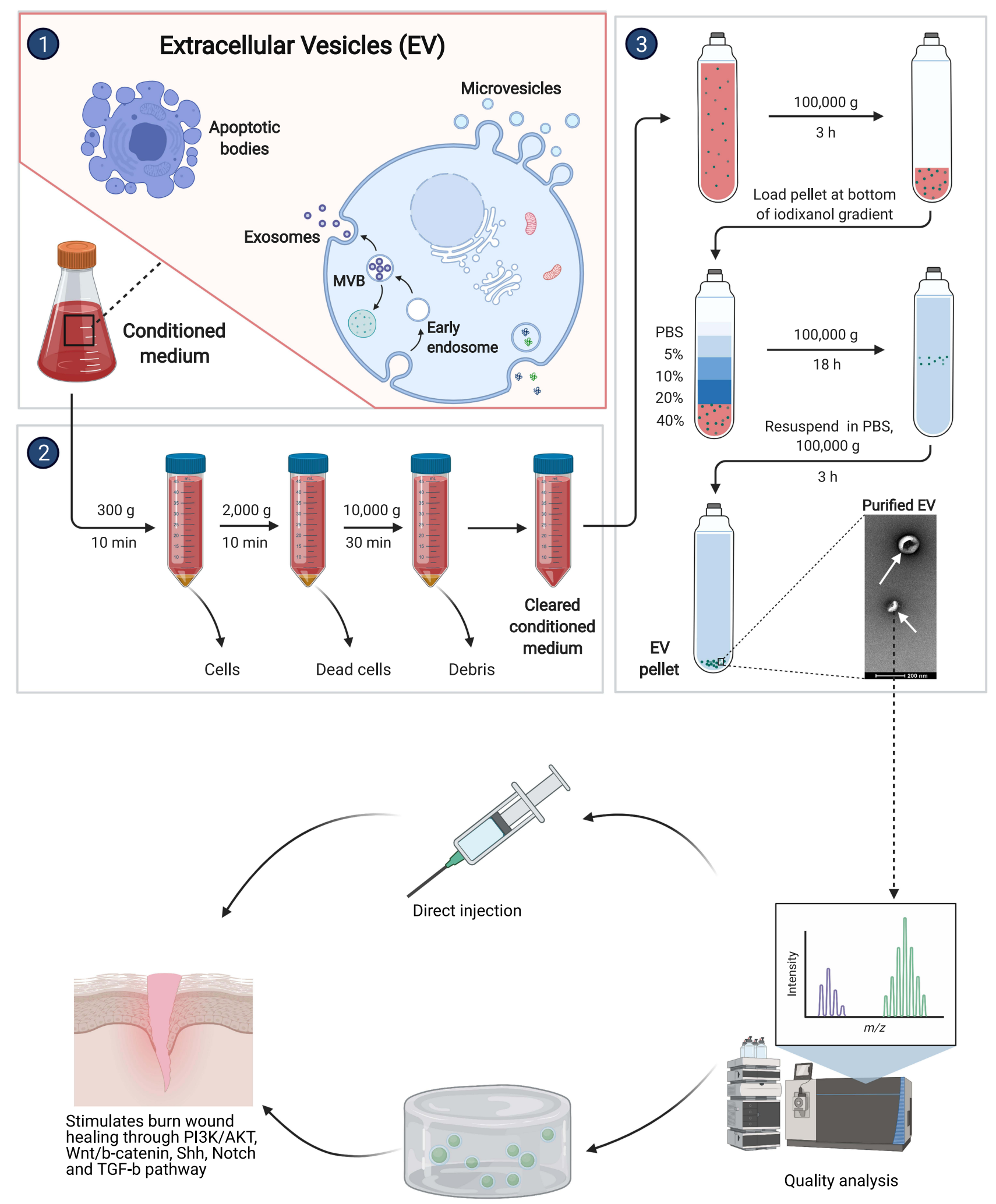

Hydrogel encapsulation

Figure 3 Exosome isolation from stem cells.

Notes: I. Schematic representing the presence of membrane-bound extracellular vesicles in media of stem cell cultures. 2. Removal of cell debris from supernatant media to subsequently purify for exosomes. 3. Exosome isolation and purification. Exosomes are a versatile therapeutic option for burn wound healing that can be either directly injected or embedded in scaffolds. Exosomes stimulate wound healing via PI3K/AKT, Wnt/b-catenin, SHH, notch and TGF-b pathways. Created with Biorender. 
dosage, route, concentration, and time of use of exosome products can be easily controlled compared to MSCs. Finally, exosomes have low chances of immune rejection and tumorigenesis. The number of exosomes and the quantity and composition of the biomolecules vary depending on the type of injury. Therefore, they are being developed as a potential therapeutic agent in burn injuries. Exosomes alleviate the limitations posed by MSCs, and they are being used in clinical applications (Figure 3). Compared to MSCs, exosomes are nano-vesicles and are more stable physiologically. They decrease cell toxicity and promote cell proliferation either directly or indirectly. ${ }^{90}$

They are involved in various signaling pathways contributing to wound healing, such as TGF $\beta$, PI3/ AKT and Notch signaling pathway. ${ }^{79}$ Exosomes derived from fetal dermal mesenchymal stem cells utilize Notch Signaling for wound healing. ${ }^{91}$ According to a study conducted by Zhang et al MSC-derived exosomes help in thermal wound healing through the WNT signaling pathway. ${ }^{92}$ As a mechanism of action executed by stem cells, PI3/AKT signaling pathway is also shown to be involved in promoting wound healing by MSC-derived exosomes. ${ }^{93}$

In terms of burn wound healing, MSC-derived exosomes can play an important role in the inflammatory phase, helping in the switch of pro-inflammatory macrophages into anti-inflammatory macrophages and regulating T cell and B cell proliferation. ${ }^{88}$ Studies show the immunomodulatory effects of exosomes inhibit inflammation at the site of wound healing and help in effective regeneration of skin. ${ }^{89,94}$ Exosomes also exert their therapeutic benefits in the proliferative phase of wound healing where they help in angiogenesis, regulate the proliferation and migration of fibroblasts, synthesize collagen, as well as reduce scar formation. ${ }^{95-97}$ Re-epithelialization and skin cell proliferative capacity of exosomes have also been shown through various studies. In diabetic rat model, exosomes have been shown to promote migration and proliferation of skin cells. ${ }^{98}$ MSC-derived exosomes are considered to be a novel therapy against delayed wound healing because of their ability to promote angiogenesis, re-epithelialization, cell proliferation and migration, and upregulating the secretion of growth factors. ${ }^{95}$

The source of exosomes influences the expression levels of growth factors secreted. Hoang et al showed that exosomes derived from three different MSC sources, such as bone marrow, adipose tissue and umbilical cord, secrete wound-healing mediated growth factors such as VEGF, FGF, Hepatocyte Growth Factor (HGF) and PDGF. The expression levels of these factors, however, varied among sources where only the umbilical cord MSC derived from exosomes showed the expression of TGF$\beta{ }^{99}$ Exosomes derived from both sources promoted fibroblast and keratinocyte migration. However, the influence of cell proliferation and migration was associated with the origin source of exosomes. Exosomes derived from BMMSC showed higher fibroblast induction, whereas UCMSC derived exosomes showed higher induction of keratinocytes. $^{99}$

\section{Conditioned Media of Stem Cells}

Like exosomes, conditioned media (CM) also contain growth factors and other secreted proteins which can be used effectively for treatment of burns (Figure 4). CM can also be massproduced and stored for long term. CM is usually collected from MSCs with low passage number as a high passage number secretes a reduced amount of angiogenic factors. ${ }^{100}$ Various paracrine factors are present in the CM which stimulate wound healing. CM is known to enhance wound healing by regulating collagen synthesis and composition, acceleration of cell proliferation and induction of angiogenesis.

Studies have previously found that CM derived from MSCs can enhance normal skin fibroblast proliferation and migration and promote wound healing in an excisional fullthickness skin murine model. ${ }^{101}$ The bioactive molecules influence neighboring cells and help in the regulation of biological processes. Human BM-MSC CM has been shown to promote healing in deep second-degree burns in male rats. ${ }^{89}$ Experimental study done by Du et al, using CM of placenta derived MSC helped in reduction of scar formation. ${ }^{100}$ Similarly, CM taken from adipose stem cells showed increased migration of MSCs through Matrigel ${ }^{102}$ promoting collagen synthesis and positively impacting wound healing. ${ }^{102}$ Growth factors such as VEGF and FGF present in the $\mathrm{CM}$ isolated from BM-MSCs, AD-SCs and amniotic fluid-derived MSCs can be the potential mediators for enhanced wound healing observed in experiments. ${ }^{13}$

The superiority of secretome does come with its own challenges. Biomolecules constituting the secretome have been difficult to characterize and pose difficulties in terms of measuring the half-life of their components. The secretome profile needs to be understood through further genetic and chemical screenings as well as next-generationproteomics and metabolomics-driven approaches. There is also inconsistency observed in the secretome profile 

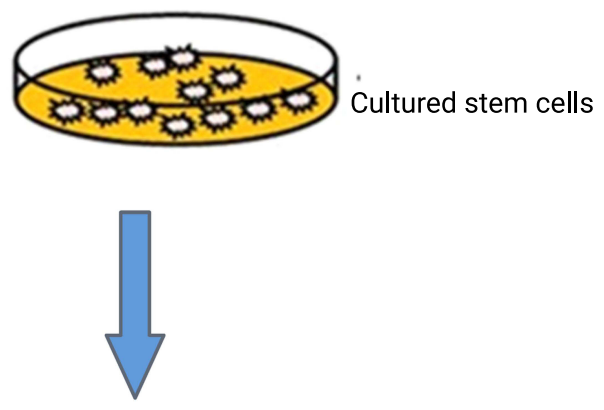

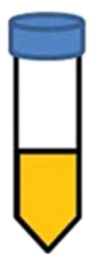

Collection of supernatant

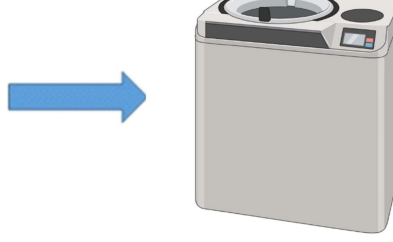

Ultracentrifugation

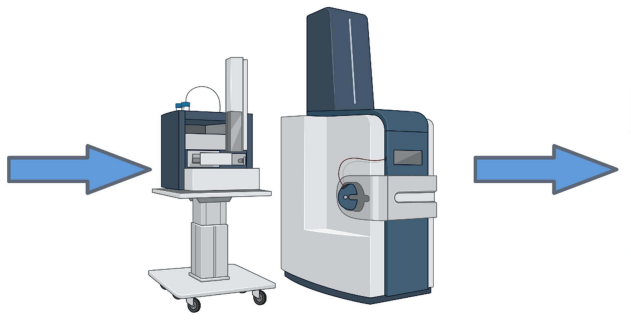

Liquid chromatography/Mass spectrometry of CM

Figure 4 Secretome of stem cells.

Notes: Supernatant media of stem cell cultures contains growth factors, cytokines, chemokines and extracellular vesicles that can be purified using ultra-centrifugation filtration units and provide the opportunity to select for certain secretome molecules based on their molecular weights. Secretome of stem cells provides a cell-free universal therapeutic option for wound healing that can potentially have the same benefit as cells but negates the challenges with viability and immune rejection.

obtained from different donors which arises from isolation and culture conditions, health condition and age of donor among many other things. These factors affect the standardization of the product. Therefore, good manufacturing protocols (GMP) need to be placed to have consistency in the products and increase the reproducibility of the secretome products.

\section{Mode of Delivery of Stem Cells and Biologics Products}

Different techniques for the administration of stem cells and their secretomes to wounds have been employed that range from direct injections to delivery in natural or synthetic biomaterials as vehicles or supporting scaffolds (Figure 5).

\section{Direct Injection}

Stem cells have been administered by researchers via direct injection either locally or through systemic injections. The majority of researchers administer MSC locally at the site of burn injury by subcutaneous or intradermal injections on full thickness, or partial thickness burns. Systemic injection involves administration of stem cells intravenously. ${ }^{11}$

Exosome treatments for burn wound therapy have involved either subcutaneous or intravenous administration.
A study by Zhang et al conducted subcutaneous injection of exosome suspended in phosphate buffer solution (PBS) in rats. Intravenous injections of exosomes have also been given in other animal models. ${ }^{95}$

\section{Scaffold-Assisted Delivery}

Different types of scaffolds are used in burn wound healing studies. The main purpose of using scaffold is to mimic the skin ECM and its properties. They facilitate cell growth, organization and differentiation into functional tissues. ${ }^{103}$ Scaffolds containing MSCs can provide a microenvironment suitable for cell adhesion, proliferation, and differentiation. ${ }^{104}$ Scaffolds are versatile and can be modified using computational modeling to withstand changes in fluid composition, cell density and mechanical stress, as well as to help in the timely release of molecules from the matrix. Some modifications of classic scaffold are made to enhance wound healing and biological activity of stem cells, such as the addition of laminin, glycosaminoglycan and fibrin, ${ }^{105}$ as well as the use of silver nanoparticles to avoid bacterial infection during healing. ${ }^{106}$

\section{Natural Material-Based Scaffolds}

Scaffolds can be made from natural materials like collagen, hyaluronic acid, fibrin and polysaccharides such as chitosan. These materials have high biocompatibility and 


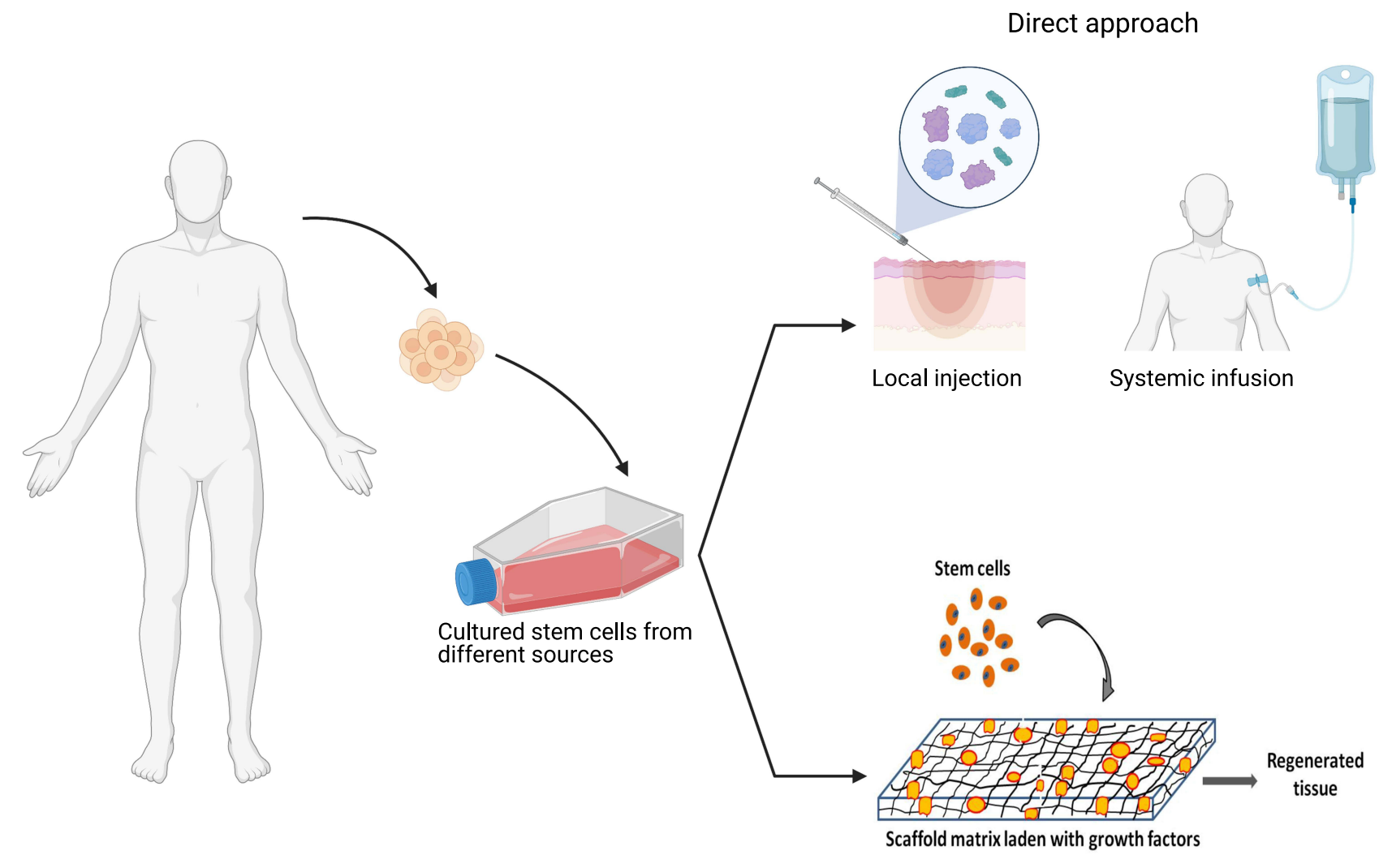

Figure 5 Different modes of delivery of stem cells/secretome for burn wounds. Stem cells and their products can be delivered onto burn wounds either as direct local injection, delivered in a supportive matrix such as fibrin or embedded with in scaffold matrices. Such approaches improve sustained delivery of therapeutics factors and/or maintain cell viability.

show enhanced epithelialization and granulation of wounds in preclinical studies. ${ }^{33}$

Collagen scaffolds containing BM-MSCs when used show promise in wound healing. In vivo studies in mice treated with MSCs seeded with collagen-based dermal substitutes show migration of cells towards areas of injury and vascularization. ${ }^{107}$ Alginate, another naturally occurring polymer obtained from seaweed, has also been used as a scaffold. Human BM-MSCs seeded in alginate gel showed viability after 6 weeks within the gel as well as significant amounts of VEGF and FGF were also found showing promising potential to be used in burn wound therapy. ${ }^{108}$ Dermal substitutes made of chitosan have antimicrobial and homeostatic activity. It is also able to stimulate re-epithelialization, collagen deposition, proliferation of fibroblasts and tissue granulation. ${ }^{109}$ Another study showed the efficacy of umbilical cord MSC seeded in modified chitosan on wound healing. Results showed increased wound closure in groups treated with MSCs seeded in modified chitosan scaffold demonstrating the potential to be used in tissue engineering. ${ }^{110}$ Modified chitosan scaffold has also been used in combination with mouse bone marrow MSCs to test burn wound healing efficacy. Mouse BM-MSCs seeded in the modified chitosan scaffold showed reduction in inflammation, reepithelialization, vascularization and granulation tissue formation in third-degree burns in mice. $^{111}$

\section{Synthetic Scaffolds}

Synthetic scaffolds are made from materials such as polyethylene glycol (PEG), polycaprolactone (PCL), polyglycolic acid (PGA) among other polymers mainly fabricated by a technique known as electrospinning. These synthetic substitutes are biocompatible and have better mechanical strength and lower cost when compared to natural scaffold. $^{112}$ Several studies have been conducted which demonstrates the efficiency of synthetic scaffolds seeded with stem cells in burn wound healing.

Treating rat models with full thickness skin wounds with electro spun poly(lactic-co-glycolic acid) (PLGA) seeded with BM-MSCs showed improved re-epithelialization. ${ }^{113}$ Adipose stem cells seeded in polymer structures made of poly(3-hydroxybutyrate-co-hydroxyvalerate) otherwise 


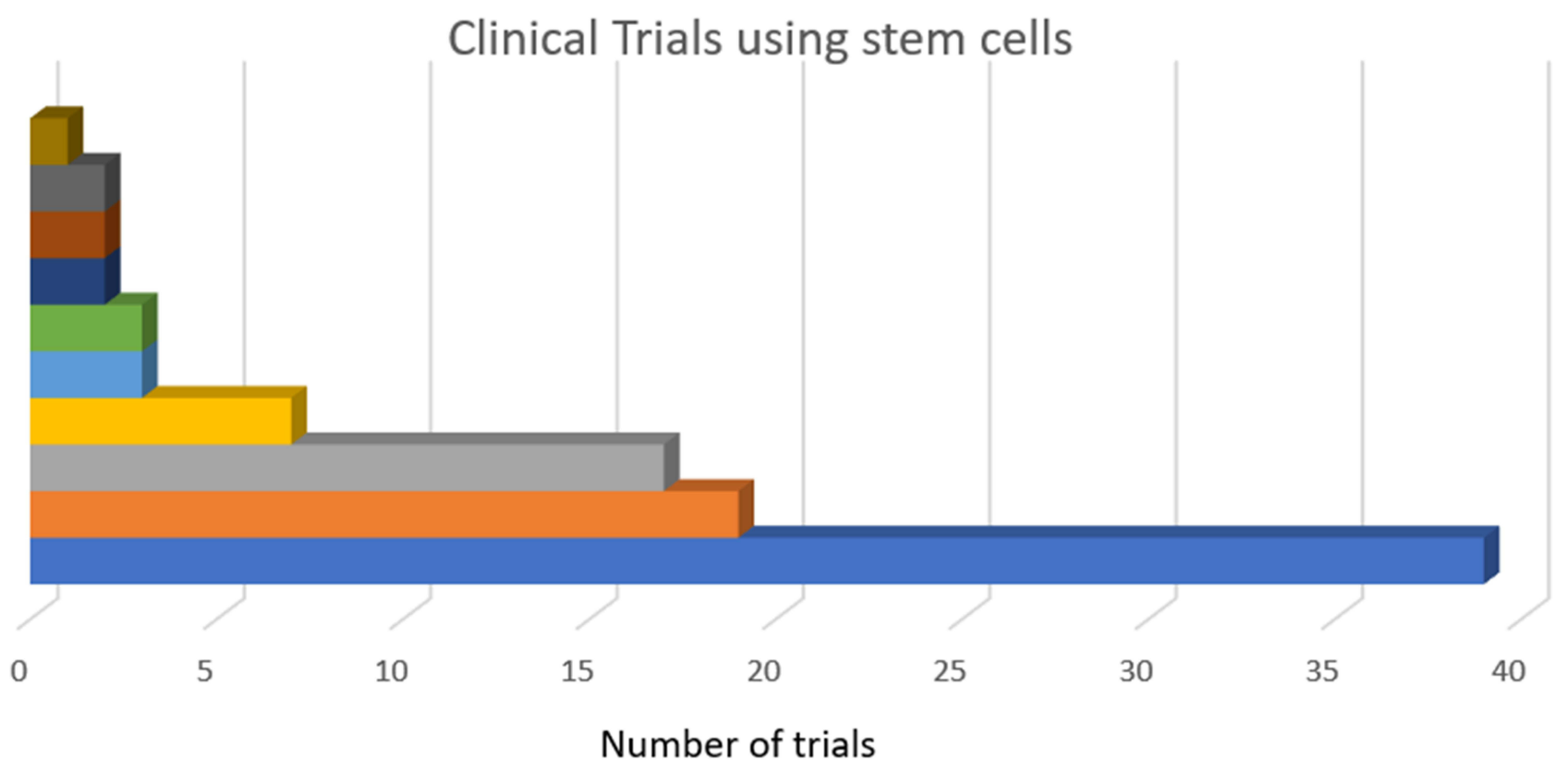

\begin{tabular}{|c|c|c|}
\hline घubstance use disorders & घ Skin & - Muscoskeletal \\
\hline 口 Digestive & Chronic respiratory diseases & Diabetes \\
\hline Mental & Neurological & Cardiovascular \\
\hline
\end{tabular}

Non-communicable diseases

Figure 6 Proportion of stem cell clinical trials in areas of skin regeneration among other indications. Note: Data adapted from Kabat et al. ${ }^{120}$

known as PHBV have shown to withstand contraction force in vivo and promote re-epithelialization, granulation, and vascularization of wounds. These structures were also able to help in the regeneration of hair follicles and sebaceous glands within 28 days. $^{109}$

\section{Human Studies and Clinical Trials}

Clinical trials are ongoing to evaluate the safety and efficacy of MSCs in burn wound healing (Figure 6). The first human trial was conducted in 2005 by Rasulov et al on a middleaged female patient who sustained burn injuries to $40 \%$ TBSA including 30\% full thickness burns. ${ }^{114}$ Treatment of burn wounds using fibroblast-like-MSCs isolated from bone marrow, at a concentration of $20-30 \times 10^{3}$ cells $/ \mathrm{cm}^{2}$ of skin showed improved vascularity, granulation, and excellent $99 \%$ graft intake. ${ }^{114}$ Similarly, in 2015, Mansilla et al treated a young man suffering from full thickness burns covering $60 \%$ TBSA with MSCs derived from bone marrow in fibrin spray at a concentration of $1 \times 10^{6}$ cells $/ 100 \mathrm{~cm}^{2}$ of skin. The results showed improved vascularity and granulation. ${ }^{114,115}$ Phase 1 trial of allogeneic MSC application to burn wounds has been done by the University of Miami to evaluate the safety of allogeneic stem cell therapy from healthy donors for second-degree burns at four different dose levels. ${ }^{116}$ This study reports the safety of MSC in treating burn wounds as well as the immunosuppressive properties of allogeneic MSCs. ${ }^{116}$ Case studies using Integra ${ }^{\mathrm{TM}}$ seeded with adipose stem cells for treating burn wounds have been done. Results show effective treatment of complex burn contractures with good functional and cosmetic outcomes. ${ }^{117}$

A recent prospective comparative study was conducted by Abo-Elkheir et al, ${ }^{118}$ which involved randomly dividing 60 patients with recent full-thickness burns into 3 groups and comparing conventional early tangential excision and meshed split-thickness skin grafts (STSGs), against locally injected autologous BM-MSCs or locally injected/topically sprayed allogeneic UC-MSCs two days following excision. The results showed that MSC therapy reduced burn-associated complications compared to STSG. ${ }^{119}$ There were no significant differences in the rate of wound healing between BM-MSC and UC-MSC treated groups. Infection complications occurred in $25 \%$ of BM- 
MSC treated groups and $70 \%$ of patients in UC-MSC treated groups. Hypertrophic scars were present in $15 \%$ of BM-MSC and 20\% UC-MSC treated groups. In case of hyperpigmentation, no hyperpigmentation occurred in BM-MSC treated groups, whereas $20 \%$ of the patients treated with UC-MSCs. ${ }^{119}$ This is the only published clinical study to date.

Reports of stem cells for burn wound healing trials are only limited to case studies that lack statistical analysis. Similarly, there are no clinical trials or case studies where stem cell secretome is used to treat burns as of date.

The number of clinical trials using stem cells on the skin is limited. Only $2 \%$ of the clinical trials using stem cells target skin and related disorders, most of which are in Phase $2 .{ }^{120}$ A large number of clinical trials occur in the USA (about $47 \%$ ) and France (16.8\%). ${ }^{120}$

\section{Conclusion and Future Perspective}

Stem cells and associated products possess huge potential in the treatment of burn wounds. The use of stem cells has proven to be superior to current strategies available for burn treatment. Experimental studies done, to date, demonstrate its potential for macro- and microscopic improvements in burn wounds and systemic anti-inflammatory effects. Stem cells and its secretome can influence the wound environment and enhance the healing process through various pathways, such as PI3K/AKT, Wnt/B-catenin, Notch, and Hedgehog. However, heterogeneity in the isolation techniques, characterization of phenotype and stem cell sources contribute to the challenges in translating their use from bench to bedside. It is hard to prove which isolation technique or stem cell source is better due to limited comparative data. Another limitation is that although positive results have been shown in small animals, translation into larger animal models is still a challenge. There is also a lack of enough published clinical trials to make an inference about the safety and efficacy of stem cells in burn wound care. Although dermal analogs, skin substitutes and tissue engineered products are promising and have reached clinical applicability, these are still not standard care for burns as they are temporary, expensive or time-consuming to prepare. Also, scaffolds used as dermal analogs do not help in the regeneration of hair follicles or sebaceous glands which, however, is improved when stem cells are used along with the scaffold. The development of new treatment approaches utilizing stem cells, or its products will need to address issues such as availability, biocompatibility, immune rejection, and vascularization. Also, the pathways undertaken by stem cells in wound repairing are not yet fully explored. The field of stem cells in burn wound care is vast and promising. With further research into pathways, standardization techniques, translation into larger animals and clinical trials, stem cells and its products can be the next standard of burn wound care.

\section{Disclosure}

The authors reported no conflicts of interest for this work.

\section{References}

1. Jeschke MG, van Baar ME, Choudhry MA, Chung KK, Gibran NS, Logsetty S. Burn injury. Nat Rev Dis Primers. 2020;6(1):11. doi:10.1038/s41572-020-0145

2. Scott-Conner CEH, Meydrech E, Wheeler WE, Coil JA. Quantitation of rate of wound closure and the prediction of death following major burns. Burns. 1988;14(5):373-378. doi:10.1016/0305-4179(88)90006-X

3. Stanojcic M, Abdullahi A, Rehou S, Parousis A, Jeschke MG. Pathophysiological response to burn injury in adults. Ann Surg. 2018;267(3):576-584. doi:10.1097/SLA.0000000000002097

4. Jeschke MG, Patsouris D, Stanojcic M, et al. Pathophysiologic response to burns in the elderly. EBioMedicine. 2015;2 (10):1536-1548. doi:10.1016/j.ebiom.2015.07.040

5. Shpichka A, Butnaru D, Bezrukov EA, et al. Skin tissue regeneration for burn injury. Stem Cell Res Ther. 2019;10(1):94. doi:10.1186/s13287-019-1203-3

6. Halim AS, Khoo TL, Mohd Yussof SJ. Biologic and synthetic skin substitutes: an overview. Indian J Plast Surg. 2010;43 (Suppl):S23-S28. doi:10.4103/0970-0358.70712

7. Stone IR, Natesan S, Kowalczewski CJ, et al. Advancements in regenerative strategies through the continuum of burn care. Front Pharmacol. 2018;9:672. doi:10.3389/fphar.2018.00672

8. Infanger M, Schmidt O, Kossmehl P, Grad S, Ertel W, Grimm D. Vascular endothelial growth factor serum level is strongly enhanced after burn injury and correlated with local and general tissue edema. Burns. 2004;30(4):305-311. doi:10.1016/j.burns.20 03.12 .006

9. Lian N, Li T. Growth factor pathways in hypertrophic scars: molecular pathogenesis and therapeutic implications. Biomed Pharmacother. 2016;84:42-50. doi:10.1016/j.biopha.2016.09. 010

10. Berlanga-Acosta J, Gavilondo-Cowley J, López-Saura P, et al. Epidermal growth factor in clinical practice - a review of its biological actions, clinical indications and safety implications. Int Wound J. 2009;6(5):331-346. doi:10.1111/j.1742-481X.2009. 00622.x

11. Francis E, Kearney L, Clover J. The effects of stem cells on burn wounds: a review. Int J Burns Trauma. 2019;9(1):1-12.

12. Ghieh F, Jurjus R, Ibrahim A, et al. The use of stem cells in burn wound healing: a review. Biomed Res Int. 2015;2015:684084. doi:10.1155/2015/684084

13. Nourian Dehkordi A, Mirahmadi Babaheydari F, Chehelgerdi M, Raeisi Dehkordi S. Skin tissue engineering: wound healing based on stem-cell-based therapeutic strategies. Stem Cell Res Ther. 2019;10(1):111. doi:10.1186/s13287-019-1212-2

14. Liu J, Ren J, Su L, et al. Human adipose tissue-derived stem cells inhibit the activity of keloid fibroblasts and fibrosis in a keloid model by paracrine signaling. Burns. 2018;44(2):370-385. doi:10.1016/j.burns.2017.08.017 
15. Fang F, Huang RL, Zheng Y, Liu M, Huo R. Bone marrow derived mesenchymal stem cells inhibit the proliferative and profibrotic phenotype of hypertrophic scar fibroblasts and keloid fibroblasts through paracrine signaling. J Dermatol Sci. 2016;83 (2):95-105. doi:10.1016/j.jdermsci.2016.03.003

16. Babakhani A, Nobakht M, Pazoki Torodi H, et al. Effects of hair follicle stem cells on partial-thickness burn wound healing and tensile strength. Iran Biomed J. 2020;24(2):99-109. doi:10.29 252/ibj.24.2.99

17. Langton AK, Herrick SE, Headon DJ. An extended epidermal response heals cutaneous wounds in the absence of a hair follicle stem cell contribution. J Invest Dermatol. 2008;128(5):13 11-1318. doi:10.1038/sj.jid.5701178

18. Zakine G, Mimoun M, Pham J, Chaouat M. Reepithelialization from stem cells of hair follicles of dermal graft of the scalp in acute treatment of third-degree burns: first clinical and histologic study. Plast Reconstr Surg. 2012;130(1):42e-50e. doi:10.1097/ PRS.0b013e318254fa21

19. Li Y, Xia WD, Van der Merwe L, Dai WT, Lin C. Efficacy of stem cell therapy for burn wounds: a systematic review and meta-analysis of preclinical studies. Stem Cell Res Ther. 2020;11(1):322. doi:10.1186/s13287-020-01839-9

20. Huang L, Burd A. An update review of stem cell applications in burns and wound care. Indian J Plast Surg. 2012;45(2):229-236. doi:10.4103/0970-0358.101285

21. Liu L, Yu Y, Hou Y, et al. Human umbilical cord mesenchymal stem cells transplantation promotes cutaneous wound healing of severe burned rats. PLoS One. 2014;9(2):e88348. doi:10.1371/ journal.pone. 0088348

22. Kim DW, Staples M, Shinozuka K, Pantcheva P, Kang SD, Borlongan CV. Wharton's jelly-derived mesenchymal stem cells: phenotypic characterization and optimizing their therapeutic potential for clinical applications. Int J Mol Sci. 2013;14 (6):11692-11712. doi:10.3390/ijms140611692

23. Zhou P, Li X, Zhang B, Shi Q, Li D, Ju X. A human umbilical cord mesenchymal stem cell-conditioned medium/chitosan/collagen/ $\beta$-glycerophosphate thermosensitive hydrogel promotes burn injury healing in mice. Biomed Res Int. 2019;20 19:5768285. doi:10.1155/2019/5768285

24. Nekanti U, Mohanty L, Venugopal P, et al. Optimization and scale-up of Wharton's jelly-derived mesenchymal stem cells for clinical applications. Stem Cell Res. 2010;5(3):244-254. doi:10. 1016/j.scr.2010.08.005

25. Choi M, Lee HS, Naidansaren $P$, et al. Proangiogenic features of Wharton's jelly-derived mesenchymal stromal/stem cells and their ability to form functional vessels. Int J Biochem Cell Biol. 2013;45(3):560-570. doi:10.1016/j.biocel.2012.12.001

26. Arno AI, Amini-Nik S, Blit PH, et al. Human Wharton's jelly mesenchymal stem cells promote skin wound healing through paracrine signaling. Stem Cell Res Ther. 2014;5(1):28. doi:10. $1186 /$ scrt417

27. Hu MS, Borrelli MR, Lorenz HP, Longaker MT, Wan DC. Mesenchymal stromal cells and cutaneous wound healing: a comprehensive review of the background, role, and therapeutic potential. Stem Cells Int. 2018;2018:6901983. doi:10.1155/2018/ 6901983

28. Cheng JZ, Farrokhi A, Ghahary A, Jalili RB. Therapeutic use of stem cells in treatment of burn injuries. J Burn Care Res. 2018;39 (2):175-182.

29. Xue L, Xu YB, Xie JL, et al. Effects of human bone marrow mesenchymal stem cells on burn injury healing in a mouse model. Int J Clin Exp Pathol. 2013;6(7):1327-1336.

30. Linard C, Brachet M, Strup-Perrot C, et al. Autologous bone marrow mesenchymal stem cells improve the quality and stability of vascularized flap surgery of irradiated skin in pigs. Stem Cells Transl Med. 2018;7(8):569-582. doi:10.1002/sctm.17-0267
31. Opalenik SR, Davidson JM. Fibroblast differentiation of bone marrow-derived cells during wound repair. FASEB J. 2005;19 (11):1561-1563. doi:10.1096/fj.04-2978fje

32. Agay D, Scherthan H, Forcheron F, et al. Multipotent mesenchymal stem cell grafting to treat cutaneous radiation syndrome: development of a new minipig model. Exp Hematol. 2010;38 (10):945-956. doi:10.1016/j.exphem.2010.06.008

33. Leonardi D, Oberdoerfer D, Fernandes MC, et al. Mesenchymal stem cells combined with an artificial dermal substitute improve repair in full-thickness skin wounds. Burns. 2012;38(8):11 43-1150. doi:10.1016/j.burns.2012.07.028

34. Wurzer P, Branski LK, Kamolz LP, Herndon DN, Finnerty CC. Fat and adipose-derived stem cell grafts in acute burns. J Burn Care Res. 2016;37(3):e302-e302. doi:10.1097/BCR.0000000000000234

35. Kern S, Eichler H, Stoeve J, Klüter H, Bieback K. Comparative analysis of mesenchymal stem cells from bone marrow, umbilical cord blood, or adipose tissue. Stem Cells. 2006;24(5):1294-1301. doi:10.1634/stemcells.2005-0342

36. Palumbo P, Lombardi F, Siragusa G, Cifone MG, Cinque B, Giuliani M. Methods of isolation, characterization and expansion of human adipose-derived stem cells (ASCs): an overview. Int J Mol Sci. 2018;19(7):1897. doi:10.3390/ijms19071897

37. Chan RK, Zamora DO, Wrice NL, et al. Development of a vascularized skin construct using adipose-derived stem cells from debrided burned skin. Stem Cells Int. 2012;2012:1-11. doi:10.1155/2012/841203

38. Trottier V, Marceau-Fortier G, Germain L, Vincent C, Fradette J. IFATS collection: using human adipose-derived stem/stromal cells for the production of new skin substitutes. Stem Cells. 2008;26(10):2713-2723. doi:10.1634/stemcells.2008-0031

39. Maharlooei MK, Bagheri M, Solhjou Z, et al. Adipose tissue derived mesenchymal stem cell (AD-MSC) promotes skin wound healing in diabetic rats. Diabetes Res Clin Pract. 2011;93(2):228-234. doi:10.1016/j.diabres.2011.04.018

40. Alexaki VI, Simantiraki D, Panayiotopoulou M, et al. Adipose tissue-derived mesenchymal cells support skin reepithelialization through secretion of KGF-1 and PDGF-BB: comparison with dermal fibroblasts. Cell Transplant. 2012;21(11):2441-2454. doi:10.3727/096368912X637064

41. Rangatchew F, Vester-Glowinski P, Rasmussen BS, et al. Mesenchymal stem cell therapy of acute thermal burns: a systematic review of the effect on inflammation and wound healing [published online ahead of print, 2020 May 15]. Burns. 2020;47(2):S0305-4179(20) 30305-3. doi:10.1016/j.burns.2020. 04.012

42. Kode JA, Mukherjee S, Joglekar MV, Hardikar AA. Mesenchymal stem cells: immunobiology and role in immunomodulation and tissue regeneration. Cytotherapy. 2009;11 (4):377-391. doi:10.1080/14653240903080367

43. Condé-Green A, Kotamarti VS, Sherman LS, et al. Shift toward mechanical isolation of adipose-derived stromal vascular fraction: review of upcoming techniques. Plast Reconstr Surg Glob Open. 2016;4(9):e1017. doi:10.1097/GOX.0000000000001017

44. Amini-Nik S, Dolp R, Eylert G, et al. Stem cells derived from burned skin - The future of burn care. EBioMedicine. 2018;37:509-520. doi:10.1016/j.ebiom.2018.10.014

45. Vinaik R, Jeschke MG. Burn-derived mesenchymal stem cells in wound healing. J Dermatol Skin Sci. 2020. Available from: https://www.dermatoljournal.com/articles/burn-derivedmesenchymal-stem-cells-in-wound-healing.html.

46. Dolp R, Eylert G, Auger C, et al. Biological characteristics of stem cells derived from burned skin-a comparative study with umbilical cord stem cells. Stem Cell Res Ther. 2021;12(1):137. doi:10.1186/s13287-021-02140-z

47. Jiang $\mathrm{W}, \mathrm{Xu}$ J. Immune modulation by mesenchymal stem cells. Cell Prolif. 2020;53(1):e12712. doi:10.1111/cpr.12712 
48. Sharma RK, John JR. Role of stem cells in the management of chronic wounds. Indian J Plast Surg. 2012;45(2):237-243. doi:10.4103/0970-0358.101286

49. Deng W, Han Q, Liao L, et al. Engrafted bone marrow-derived flk-(1+) mesenchymal stem cells regenerate skin tissue. Tissue Eng. 2005;11(1-2):110-119. doi:10.1089/ten.2005.11.110

50. Lee JY, Oh N, Park KS. Ell3 modulates the wound healing activity of conditioned medium of adipose-derived stem cells. Dev Reprod. 2017;21(3):335-342. doi:10.12717/DR.2017.21.3.335

51. Kato T, Khanh VC, Sato K, et al. SDF-1 improves wound healing ability of glucocorticoid-treated adipose tissue-derived mesenchymal stem cells [published correction appears in Biochem Biophys Res Commun. 2018 Feb 8]. Biochem Biophys Res Commun. 2017;493 (2):1010-1017. doi:10.1016/j.bbrc.2017.09.100

52. Hu MS, Rennert RC, McArdle A, et al. The role of stem cells during scarless skin wound healing. Adv Wound Care (New Rochelle). 2014;3(4):304-314. doi:10.1089/wound.2013.0471

53. Uysal CA, Tobita M, Hyakusoku H, Mizuno H. The effect of bone-marrow-derived stem cells and adipose-derived stem cells on wound contraction and epithelization. Adv Wound Care (New Rochelle). 2014;3(6):405-413. doi:10.1089/wound.2014.0539

54. Lo Monaco M, Merckx G, Ratajczak J. Stem cells for cartilage repair: preclinical studies and insights in translational animal models and outcome measures. Stem Cells Int. 2018;20 18:9079538. doi:10.1155/2018/9079538

55. Castilho RM, Squarize CH, Gutkind JS. Exploiting PI3K/mTOR signaling to accelerate epithelial wound healing. Oral Dis. 2013;19(6):551-558. doi:10.1111/odi.12070

56. Li J-Y, Ren -K-K, Zhang W-J, et al. Human amniotic mesenchymal stem cells and their paracrine factors promote wound healing by inhibiting heat stress-induced skin cell apoptosis and enhancing their proliferation through activating PI3K/AKT signaling pathway. Stem Cell Res Ther. 2019;10(1):247. doi:10.1186/ s13287-019-1366-y

57. Chen J, Crawford R, Chen C, Xiao Y. The key regulatory roles of the PI3K/Akt signaling pathway in the functionalities of mesenchymal stem cells and applications in tissue regeneration. Tissue Eng Part B Rev. 2013;19(6):516-528. doi:10.1089/ten. TEB.2012.0672

58. Mangi AA, Noiseux N, Kong D, et al. Mesenchymal stem cells modified with Akt prevent remodeling and restore performance of infarcted hearts. Nat Med. 2003;9(9):1195-1201. doi:10.1038/ nm912

59. Xiao W, Tang H, Wu M, et al. Ozone oil promotes wound healing by increasing the migration of fibroblasts via PI3K/Akt/mTOR signaling pathway. Biosci Rep. 2017;37(6):6. doi:10.1042/BSR20170658

60. Li G, Li -Y-Y, Sun J-E, Lin W-H, Zhou R-X. ILK-PI3K/AKT pathway participates in cutaneous wound contraction by regulating fibroblast migration and differentiation to myofibroblast. $L a b$ Invest. 2016;96(7):741-751. doi:10.1038/labinvest.2016.48

61. Charette ST, McCance DJ. The E7 protein from human papillomavirus type 16 enhances keratinocyte migration in an Akt-dependent manner. Oncogene. 2007;26(52):7386-7390. doi:10.1038/sj.onc.1210541

62. Kapoor M, Liu S, Shi-wen X, et al. GSK-3beta in mouse fibroblasts controls wound healing and fibrosis through an endothelin-1-dependent mechanism [retracted in: J Clin Invest. 2008 Nov;118(11):3812]. J Clin Invest. 2008;118(10):3279-3290. doi:10.1172/JCI35381

63. Kim JA, Choi HK, Kim TM, Leem SH, Oh IH. Regulation of mesenchymal stromal cells through fine tuning of canonical Wnt signaling. Stem Cell Res. 2015;14(3):356-368. doi:10.1016/j. scr.2015.02.007

64. Cai SX, Liu A, Chen $\mathrm{S}$, et al. Activation of $\mathrm{Wnt} / \beta$-catenin signalling promotes mesenchymal stem cells to repair injured alveolar epithelium induced by lipopolysaccharide in mice. Stem Cell Res Ther. 2015;6(1):65. doi:10.1186/s13287-015-0060-y
65. Hoffman MD, Benoit DS. Agonism of Wnt- $\beta$-catenin signalling promotes mesenchymal stem cell (MSC) expansion. J Tissue Eng Regen Med. 2015;9(11):E13-E26. doi:10.1002/term.1736

66. Xu X, Zhang L, He X, et al. TGF- $\beta$ plays a vital role in triplenegative breast cancer (TNBC) drug-resistance through regulating stemness, EMT and apoptosis. Biochem Biophys Res Commun. 2018;502(1):160-165. doi:10.1016/j.bbrc.2018.05.139

67. Bielefeld KA, Amini-Nik S, Whetstone H, et al. Fibronectin and beta-catenin act in a regulatory loop in dermal fibroblasts to modulate cutaneous healing. J Biol Chem. 2011;286(31): 27687-27697. doi:10.1074/jbc.M111.261677

68. Shi Y, Shu B, Yang R, et al. Wnt and Notch signaling pathway involved in wound healing by targeting c-Myc and Hes1 separately [published correction appears in Stem Cell Res Ther. 2015;6:254]. Stem Cell Res Ther. 2015;6(1):120. doi:10.1186/ s13287-015-0103-4

69. Allison JC, Toby MH, Patricia B, Mark WJF. Expression of TGF-beta and its receptors in murine fetal and adult dermal wounds. Eur J Dermatol. 2001;11(5):424-431.

70. Tyrone JW, Marcus JR, Bonomo SR, Mogford JE, Xia Y, Mustoe TA. Transforming growth factor beta3 promotes fascial wound healing in a new animal model. Arch Surg. 2000;135 (10):1154-1159. doi:10.1001/archsurg.135.10.1154

71. Puolakkainen PA, Reed MJ, Gombotz WR, Twardzik DR, Abrass IB, Sage HE. Acceleration of wound healing in aged rats by topical application of transforming growth factor-beta(1). Wound Repair Regen. 1995;3(3):330-339. doi:10.1046/j.1524475X.1995.t01-1-30314.x

72. Yoon BS, Moon JH, Jun EK, et al. Secretory profiles and wound healing effects of human amniotic fluid-derived mesenchymal stem cells. Stem Cells Dev. 2010;19(6):887-902. doi:10.1089/ scd.2009.0138

73. Jiang T, Wang Z, Sun J. Human bone marrow mesenchymal stem cell-derived exosomes stimulate cutaneous wound healing mediates through TGF- $\beta /$ Smad signaling pathway. Stem Cell Res Ther. 2020;11(1):198. doi:10.1186/s13287-020-01723-6

74. Zhang T, Wang XF, Wang ZC, et al. Current potential therapeutic strategies targeting the TGF- $\beta /$ Smad signaling pathway to attenuate keloid and hypertrophic scar formation. Biomed Pharmacother. 2020;129:110287. doi:10.1016/j.biopha.2020.110287

75. Pakyari M, Farrokhi A, Maharlooei MK, Ghahary A. Critical role of transforming growth factor beta in different phases of wound healing. Adv Wound Care (New Rochelle). 2013;2(5):215-224. doi:10.1089/wound.2012.0406

76. Ghadially R. 25 years of epidermal stem cell research. J Invest Dermatol. 2012;132(3 Pt 2):797-810. doi:10.1038/jid.2011.434

77. Pedrosa AR, Trindade A, Fernandes AC, et al. Endothelial Jagged1 antagonizes D114 regulation of endothelial branching and promotes vascular maturation downstream of D114/Notch1. Arterioscler Thromb Vasc Biol. 2015;35(5):1134-1146. doi:10. 1161/ATVBAHA.114.304741

78. Chigurupati S, Arumugam TV, Son TG, et al. Involvement of notch signaling in wound healing. PLoS One. 2007;2(11):e1167. doi:10.1371/journal.pone.0001167

79. Wang X, Jiao Y, Pan Y, et al. Fetal dermal mesenchymal stem cell-derived exosomes accelerate cutaneous wound healing by activating notch signaling. Stem Cells Int. 2019;2019:2402916. doi:10.1155/2019/2402916

80. Moriyama H, Moriyama M, Ozawa $\mathrm{T}$, et al. Notch signaling enhances stemness by regulating metabolic pathways through

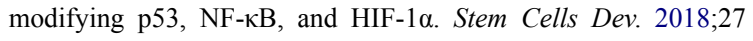
(13):935-947. doi:10.1089/scd.2017.0260

81. Mutyaba PL, Belkin NS, Lopas L, et al. Notch signaling in mesenchymal stem cells harvested from geriatric mice. J Orthop Trauma. 2014;28(Suppl 1):S20-S23. doi:10.1097/BOT.0000000 000000064 
82. Balint K, Xiao M, Pinnix CC, et al. Activation of Notch1 signaling is required for beta-catenin-mediated human primary melanoma progression. J Clin Invest. 2005;115(11):3166-3176. doi:10.1172/JCI25001

83. Outtz HH, Wu JK, Wang X, Kitajewski J. Notch1 deficiency results in decreased inflammation during wound healing and regulates vascular endothelial growth factor receptor-1 and inflammatory cytokine expression in macrophages. $J$ Immunol. 2010;185(7):4363-4373. doi:10.4049/jimmunol.1000720

84. Suh HN, Han HJ. Sonic hedgehog increases the skin wound-healing ability of mouse embryonic stem cells through the microRNA 200 family. $B r \quad J$ Pharmacol. 2015;172 (3):815-828. doi:10.1111/bph.12947

85. Zavala G, Prieto CP, Villanueva AA, Palma V. Sonic hedgehog (SHH) signaling improves the angiogenic potential of Wharton's jelly-derived mesenchymal stem cells (WJ-MSC). Stem Cell Res Ther. 2017;8(1):203. doi:10.1186/s13287-017-0653-8

86. Asai J, Takenaka H, Kusano KF, et al. Topical sonic hedgehog gene therapy accelerates wound healing in diabetes by enhancing endothelial progenitor cell-mediated microvascular remodeling. Circulation. 2006;113(20):2413-2424. doi:10.1161/CIRCULATIONAHA.105. 603167

87. Lo Sicco C, Reverberi D, Balbi C, et al. Mesenchymal stem cell-derived extracellular vesicles as mediators of anti-inflammatory effects: endorsement of macrophage polarization. Stem Cells Transl Med. 2017;6(3):1018-1028. doi:10.1002/sctm.16-0363

88. Ti D, Hao H, Tong C, et al. LPS-preconditioned mesenchymal stromal cells modify macrophage polarization for resolution of chronic inflammation via exosome-shuttled let-7b. J Transl Med. 2015;13(1):308. doi:10.1186/s12967-015-0642-6

89. Aryan A, Bayat M, Bonakdar S, et al. Human bone marrow mesenchymal stem cell conditioned medium promotes wound healing in deep second-degree burns in male rats. Cells Tissues Organs. 2018;206(6):317-329. doi:10.1159/000501651

90. Yu B, Zhang X, Li X. Exosomes derived from mesenchymal stem cells. Int $J$ Mol Sci. 2014;15(3):4142-4157. doi:10.3390/ ijms 15034142

91. Geiger A, Walker A, Nissen E. Human fibrocyte-derived exosomes accelerate wound healing in genetically diabetic mice. Biochem Biophys Res Commun. 2015;467(2):303-309. doi:10.10 16/j.bbrc.2015.09.166

92. Ding J, Wang X, Chen B, Zhang J, Xu J. Exosomes derived from human bone marrow mesenchymal stem cells stimulated by deferoxamine accelerate cutaneous wound healing by promoting angiogenesis. Biomed Res Int. 2019;2019:9742765. doi:10.1155/ 2019/9742765

93. Li B, Luan S, Chen J, et al. The MSC-derived exosomal lncRNA H19 promotes wound healing in diabetic foot ulcers by upregulating PTEN via MicroRNA-152-3p. Mol Ther Nucleic Acids. 2020;19:814-826. doi:10.1016/j.omtn.2019.11.034

94. Hu L, Wang J, Zhou X, et al. Exosomes derived from human adipose mesenchymal stem cells accelerates cutaneous wound healing via optimizing the characteristics of fibroblasts. Sci Rep. 2016;6(1):32993. doi:10.1038/srep32993

95. Zhang B, Wang M, Gong A, et al. HucMSC-exosome mediated-wnt4 signaling is required for cutaneous wound healing. Stem Cells. 2015;33(7):2158-2168. doi:10.1002/stem. 1771

96. Sahoo S, Klychko E, Thorne T, et al. Exosomes from human CD34(+) stem cells mediate their proangiogenic paracrine activity. Circ Res. 2011;109(7):724-728. doi:10.1161/ CIRCRESAHA.111.253286

97. Wu P, Zhang B, Shi H, Qian H, Xu W. MSC-exosome: a novel cell-free therapy for cutaneous regeneration. Cytotherapy. 2018;20(3):291-301. doi:10.1016/j.jcyt.2017.11.002
98. Li M, Wang T, Tian H, Wei G, Zhao L, Shi Y. Macrophagederived exosomes accelerate wound healing through their anti-inflammation effects in a diabetic rat model. Artif Cells Nanomed Biotechnol. 2019;47(1):3793-3803. doi:10.1080/ 21691401.2019.1669617

99. Hoang DH, Nguyen TD, Nguyen HP, et al. Differential wound healing capacity of mesenchymal stem cell-derived exosomes originated from bone marrow, adipose tissue and umbilical cord under serum- and xeno-free condition. Front Mol Biosci. 2020;7:119. doi:10.3389/fmolb.2020.00119

100. Du L, Lv R, Yang X, Cheng S, Ma T, Xu J. Hypoxic conditioned medium of placenta-derived mesenchymal stem cells protects against scar formation. Life Sci. 2016;149:51-57. doi:10.1016/j. Ifs.2016.02.050

101. Im GB, Kim YH, Kim YJ, et al. Enhancing the wound healing effect of conditioned medium collected from mesenchymal stem cells with high passage number using bioreducible nanoparticles. Int J Mol Sci. 2019;20(19):4835. doi:10.3390/ijms20194835

102. Lee EY, Xia Y, Kim WS, et al. Hypoxia-enhanced wound-healing function of adipose-derived stem cells: increase in stem cell proliferation and up-regulation of VEGF and bFGF. Wound Repair Regen. 2009;17(4):540-547. doi:10.1111/j.1524-475X.20 09.00499.x

103. Guo X, Xia B, Lu XB, et al. Grafting of mesenchymal stem cell-seeded small intestinal submucosa to repair the deep partial-thickness burns. Connect Tissue Res. 2016;57(5):3 88-397. doi:10.1080/03008207.2016.1193173

104. Kucharzewski M, Rojczyk E, Wilemska-Kucharzewska K, Wilk R, Hudecki J, Los MJ. Novel trends in application of stem cells in skin wound healing. Eur J Pharmacol. 2019;84 3:307-315. doi:10.1016/j.ejphar.2018.12.012

105. Tottoli EM, Dorati R, Genta I, Chiesa E, Pisani S, Conti B. Skin wound healing process and new emerging technologies for skin wound care and regeneration. Pharmaceutics. 2020;12(8):735. doi:10.3390/pharmaceutics12080735

106. Pérez-Díaz MA, Silva-Bermudez P, Jiménez-López B, et al. Silverpig skin nanocomposites and mesenchymal stem cells: suitable antibiofilm cellular dressings for wound healing. J Nanobiotechnology. 2018;16(1):2. doi:10.1186/s12951-017-0331-0

107. Negut I, Dorcioman G, Grumezescu V. Scaffolds for wound healing applications. Polymers (Basel). 2020;12(9):2010. doi:10.3390/polym12092010

108. Schmitt A, Rödel P, Anamur C, et al. Calcium alginate gels as stem cell matrix-making paracrine stem cell activity available for enhanced healing after surgery. PLoS One. 2015;10(3):e0118937. doi:10.1371/journal.pone.0118937

109. Tartarini D, Mele E. Adult stem cell therapies for wound healing: biomaterials and computational models. Front Bioeng Biotechnol. 2016;3:206. doi:10.3389/fbioe.2015.00206

110. Zeinali R, Biazar E, Keshel SH, Tavirani MR, Asadipour K. Regeneration of full-thickness skin defects using umbilical cord blood stem cells loaded into modified porous scaffolds. ASAIO J. 2014;60(1):106-114. doi:10.1097/MAT.00000000000 00025

111. Alapure BV, Lu Y, He M, et al. Accelerate healing of severe burn wounds by mouse bone marrow mesenchymal stem cell-seeded biodegradable hydrogel scaffold synthesized from arginine-based poly(ester amide) and chitosan. Stem Cells Dev. 2018;27 (23):1605-1620. doi:10.1089/scd.2018.0106

112. Nikolova MP, Chavali MS. Recent advances in biomaterials for 3D scaffolds: a review. Bioact Mater. 2019;4:271-292. doi:10. 1016/j.bioactmat.2019.10.005

113. Zonari A, Martins TM, Paula AC, et al. Polyhydroxybutyrate-cohydroxyvalerate structures loaded with adipose stem cells promote skin healing with reduced scarring. Acta Biomater. 2015;17:170-181. doi:10.1016/j.actbio.2015.01.043 
114. Ahmadi AR, Chicco M, Huang J, et al. Stem cells in burn wound healing: a systematic review of the literature. Burns. 2019;45 (5):1014-1023. doi:10.1016/j.burns.2018.10.017

115. Schulman CI, Candanedo A, Rodriguez-Menocal L, et al. 354 Clinical trial of allogeneic mesenchymal stem cells in second degree burns: prelim results. J Burn Care Res. 2018;39 (suppl_1):S147-S147. doi:10.1093/jbcr/iry006.276

116. Mansilla E, Marín GH, Berges M, et al. Cadaveric bone marrow mesenchymal stem cells: first experience treating a patient with large severe burns. Burns Trauma. 2015;3:17. doi:10.1186/ s41038-015-0018-4

117. Mashiko T, Takada $\mathrm{H}$, Wu SH, et al. Therapeutic effects of a recombinant human collagen peptide bioscaffold with human adipose-derived stem cells on impaired wound healing after radiotherapy. J Tissue Eng Regen Med. 2018;12(5):1186-1194. doi:10.1002/term.2647

118. Abo-Elkheir W, Hamza F, Elmofty AM, et al. Role of cord blood and bone marrow mesenchymal stem cells in recent deep burn: a Case-Control Prospective Study. Am J Stem Cells. 2017;6(3):23-35.
119. Rangatchew F, Vester-Glowinski P, Rasmussen BS, et al. Mesenchymal stem cell therapy of acute thermal burns: a systematic review of the effect on inflammation and wound healing. Burns. 2021;47(2):270-294. doi:10.1016/j.burns.2020.04.012

120. Kabat M, Bobkov I, Kumar S, Grumet M. Trends in mesenchymal stem cell clinical trials 2004-2018: is efficacy optimal in a narrow dose range? Stem Cells Transl Med. 2020;9(1):17-27. doi:10.1002/sctm.19-0202

121. Chua AWC, Khoo YC, Tan BK, Tan KC, Foo CL, Chong SJ. Skin tissue engineering advances in severe burns: review and therapeutic applications Burns \& Trauma. 2016;4:s41038-016-0027y. doi:10.1186/s41038-016-0027-y

\section{Publish your work in this journal}

Biologics: Targets and Therapy is an international, peer-reviewed journal focusing on the patho-physiological rationale for and clinical application of Biologic agents in the management of autoimmune diseases, cancers or other pathologies where a molecular target can be identified. This journal is indexed on PubMed Central, CAS, EMBase,
Scopus and the Elsevier Bibliographic databases. The manuscript management system is completely online and includes a very quick and fair peer-review system, which is all easy to use. Visit http://www.dovepress.com/testimonials.php to read real quotes from published authors. 